\title{
How Auctions Amplify House-Price Fluctuations
}

\author{
Alina Arefeva* \\ Stanford University \\ Download current version at www.stanford.edu/ aarefeva/ \\ First draft: May 29, 2015 \\ This draft: February 14, 2016
}

\begin{abstract}
I develop a tractable dynamic model of the housing market where the prices are determined in auctions rather than by Nash bargaining as in the standard housing search model. Markets that use auctions mimic actual housing markets, in that the model can portray a "hot" market where numerous buyers flock to each new house on the market and a "cold" market, where numerous houses are on the market and a buyer has a wide choice without competing directly with other buyers. In the auction model prices are higher, the market is bigger and waiting times are longer in the steady state compared to the standard model. In particular, the house prices are thirty percent higher in the auction model than in the bargaining model. There are four times more buyers and sellers and it takes four times longer to buy or sell a house in steady state. The dynamic response of prices to shocks is larger in the auction model than in the bargaining model. Auctions amplify the response of house prices to shocks because prices respond more to changes in the present value of the housing services, and the option value to sell is more sensitive to the state of the housing market. The equilibrium allocations of the auction and Nash bargaining model are not socially efficient, so the government interventions are desirable.

Keywords: housing, real estate, volatility, search and matching, pricing, liquidity, Nash bargaining, auctions, bidding wars

JEL codes: C78, D44, D83, E30, E44, R21, R31
\end{abstract}

*I am grateful for the support and guidance of my advisors Robert Hall, Monika Piazzesi, Pablo Kurlat. I thank Nick Arefiev, Kirill Borusyak, John Cochrane, Darrell Duffie, Dave Donaldson, Liran Einav, Phil Hubbard, Eran Hoffmann, Caroline Hoxby, Kenneth L. Judd, Ivan Korolev, Pavel Krivenko, Brad Larsen, Moritz Lenel, Han Lu, Delong Meng, Paul Milgrom, Espen Moen, Plamen Nenov, Elena Pastorino, Martin Schneider, Ilya Segal, Alexey Suzdaltsev, Christopher Tonetti, Alonso Villacorta, Sergey Vorontsov and seminar participants at Stanford and 2015 Bay Area Macro-Finance-Trade Student Conference at Berkeley for helpful discussions, and the Hoover Institution for financial support. 


\section{Introduction}

Housing wealth comprises around two thirds of the household wealth in the US1 The housing wealth is determined by a value of house inventory, and hence housing prices. Studying how house prices are determined is thus critical for understanding the movements in an economy's wealth.

The literature has established that the US and UK housing markets switch between hot and cold markets (Ngai and Tenreyro (2014)). Hot markets have rising prices, many sales, a low inventory of homes, and multiple offers for each house on the market, resulting in quick sale (Han and Strange (2012)). In contrast, cold markets have stagnating prices, depressed sales, high inventory, infrequent offers, and long selling times. These price movements are persistent Head, Lloyd-Ellis, and Sun (2014) document that the house prices fluctuate more relative to the predictions of the standard asset pricing model and that house price growth has high positive autocorrelation over the short run.

Buyers and sellers of houses engage in time-consuming search, so modeling of housing markets has tended to adopt the search and matching model of Diamond, Mortensen, and Pissarides $2^{2}$ originally developed to study the labor market. In that model, prices are formed in a bargain between a single seller and a single buyer. The model incorporates the Nash bargaining solution, where the price splits the joint surplus of the buyer and the seller with weights equal to their bargaining powers.

The assumption that price determination occurs only in bilateral bargaining is restrictive and fails to describe the actual operation of the housing market. In practice, hot market episodes occur frequently. In those episodes, a seller deals with multiple interested buyers simultaneously. An auction is a natural way to model these episodes. This paper explores the implications of the auction-based price setting mechanism in the housing market for the level of prices, market size, welfare, housing liquidity, and how the housing market reacts to shocks.

This paper contributes to the debate on why house prices are volatile, by developing a tractable dynamic search model of the local housing market with an auction as a trading mechanism. The intuition of the model is that incentives of a buyer and a seller to achieve an agreement on the sale price vary between the hot and cold market. In "hot" markets many potential buyers are active in the market and swarm to any house that comes on the market. A seller has a reservation price, but expects to sell above the reservation price. The selling price is found quickly through an auction. By contrast, in "cold" markets, many potential houses linger on the market. A buyer has time to keep looking for the house, and the houses will sell at prices close to the reservation price of the sellers. My model incorporates these features of the housing market, with the aim of explaining the fluctuations of prices between the hot and cold markets. I show that the model with auctions embodies a new mechanism that increases the volatility of house prices compared to the benchmark bargaining model.

Compared to the Nash bargaining model, in the auction model prices are higher, the market is bigger and waiting times are longer. Specifically, house prices are thirty percent higher in the auction model than in the Nash bargaining model. There are four times more buyers and sellers

\footnotetext{
${ }^{1}$ Flow of Funds, see, for example, Piazzesi and Schneider (2012), Favilukis, Ludvigson, and Nieuwerburgh (2015).

$\sqrt[2]{\text { Mortensen and Pissarides }}(1994)$
} 
and it takes four times longer to buy or sell a house in steady state. The response of prices to shocks is larger in the auction model than in the Nash bargaining model. Auctions amplify the response of house prices to shocks because prices respond more to changes in the present value of the housing services, and the option value to sell is more sensitive to the state of the housing market.

The response of prices to exogenous shocks is more pronounced in the auction model than in the Nash bargaining model, which helps explain swings of house prices from boom to bust. Longer times to sell slow down the mean-reversion of house prices after a shock, sometimes referred to as momentum, which accounts for the positive autocorrelation in the house price growth observed in the data.

The rest of the paper is organized as follows. Section 2 highlights the contribution of the paper to the literature. Section 3 builds a housing search model which allows for several buyers to be matched to one seller who runs an auction to determine the sale price. Then this auction search model is compared with otherwise identical search model where the price is set as a Nash bargaining solution of one-to-one negotiation between a buyer and a seller. Section 4 calibrates parameters of both models based on data from the U.S. housing markets and quantifies the differences in prices, house liquidity, the price persistence and responsiveness of prices to demand shocks. Section 5 discusses the social efficiency of the equilibrium allocations in the auction and Nash bargaining models.

\section{Related Literature}

The paper builds on the growing literature of housing search and matching ${ }^{3}$ which is summarized in Han and Strange (2015). The model with the bargaining price determination mechanism in the present study is closest to the models in Head, Lloyd-Ellis, and Sun (2014) and Díaz and Jerez (2013) who consider a random search and matching model of the housing market. This paper constructs the auction search model of the housing market in addition to the bargaining model to highlight the importance of the price determination mechanism for the joint dynamics of house prices, sales and liquidity.

Han and Strange (2015) observe that the theoretical literature on real-estate auctions is sparse. A closely related paper to mine is Albrecht, Gautier, and Vroman (2015), which builds a static directed search model with an auction to study the role of the asking price in the housing market. By constrast, my paper considers a dynamic random search model and abstracts from the asking price as a signaling mechanism. The aim is to isolate the implications of the auction price-finding process against the Nash bargain. The dynamic framework makes it possible to take into account the option values of buying and selling the house later that propagate the housing market shocks.

3 Wheaton (1990), Krainer (2001), Albrecht, Anderson, Smith, and Vroman (2007), Piazzesi and Schneider (2009), Novy-Marx (2009), Caplin and Leahy (2011), Carrillo (2012), Genesove and Han (2012), Anenberg and Bayer (2013), Burnside, Eichenbaum, and Rebelo (2013), Díaz and Jerez (2013), Ngai and Tenreyro (2014), Piazzesi, Schneider, and Stroebel (2014), Head, Lloyd-Ellis, and Sun (2014), Head, Lloyd-Ellis, and Stacey (2014), Guren (2014), Guren and McQuade (2013), Ngai and Sheedy (2015), Moen, Nenov, and Sniekers (2015) 
Genesove and Hansen (2014) compare the time-series properties of the housing auction prices and the prices, determined in a private-treaty negotiation, in the two largest Australian cities to argue that using the average auction prices can improve predictability of the average sale prices overall. My paper complements Genesove and Hansen (2014) paper in assessing the differences of predictions of auction and Nash bargaining prices, but it explicitly considers the option value to buy and sell in the dynamic setting and incorporates search frictions to highlight importance of the ratio of buyers to sellers in intermediating large movements in transaction prices. The predictions of this paper are consistent with the empirical evidence in Genesove and Hansen (2014), - see Section 4.

Quan (2002) builds a static model where the buyers and seller choose between the markets with the auction and bargaining price determination mechanisms. The model predicts 30 percent higher prices in the auction as compared to the bargaining which is confirmed empirically based on the MLS data from the Austin metropolitan area. The model in this paper abstracts from the endogenous choice between two mechanism and focuses on the predictions of the auction and Nash bargaining price determination mechanisms in the dynamic setting rather than static as in Quan (2002). However, in the steady state of the dynamic model in this paper, the house prices are 30 percent higher in the auction model as compared to the search model with one-to-one bargaining consistent with Quan (2002).

In order to focus on the implications of the sales mechanism and make models tractable, I abstract from some features of the housing market. First, I assume that once a homeowner has moved into a house, she is never separated from the house. The possibility of resale and turnover of housing stock is potentially an important channel that is discussed, for example, in Anenberg and Bayer (2013), Head, Lloyd-Ellis, and Sun (2014), Piazzesi, Schneider, and Stroebel (2014), Moen, Nenov, and Sniekers (2015). Second, I consider a random search model since the price paid by a buyer in an auction is unknown prior to participating in one. Competitive search models

where buyers direct their search based on the price are discussed in Carrillo (2012), Albrecht, Gautier, and Vroman (2015), Head, Lloyd-Ellis, and Stacey (2014). Third, I do not model the mortgage market, which is extensively studied in the housing literature, see, for example, Favilukis, Ludvigson, and Nieuwerburgh (2015) and Landvoigt (2014). The interaction of the search frictions and credit constraints is explored in Guren and McQuade (2013) and Hedlund (2015).

\section{Models}

In this section I consider two search models of the local housing market that have the same building blocks, except for the price determination mechanism.

\subsection{Elements Common to Both Models}

Time is discrete $t \in\{0,1, \ldots\}$, and the interest rate $r$ is fixed. There are two goods in the economy, consumption, taken as the numeraire, and housing; and two markets corresponding to these goods. Housing can be consumed only in quantities zero or one. A unit of owner-occupied housing provides a flow of services $x$. The consumption market is frictionless, while the housing 
market requires a buyer to search. If an agent wants to consume a unit of housing, he has to buy a house which involves searching for the property. Every buyer rents a place in the competitive rental market at price $w$ until moving into a purchased house. The service flow from the rental housing is normalized to zero.

There are infinitely-lived risk-neutral agents with the discount factor $\beta=1 /(1+r)$. There are two types of these agents: buyers and sellers. A seller has a house, but does not receive housing services from the house. The measure of sellers in period $t$ is $S_{t}$. A buyer draws a match-specific random level of housing services $x$, at the time when the buyer tours the house. These values are independent and identically distributed over time and buyers. Buyers live forever after in the house starting the next period and receive the unchanging flow of services $x$.

The measure of buyers in period $t$ is $B_{t}$. Each period every buyer and seller chooses whether to pay fixed search costs per period. If a seller (buyer) has paid search costs, she is called active and can put a house on sale (search for a house to buy). Let $S_{t}^{a}$ and $B_{t}^{a}$ be the measures of active sellers and buyers, correspondingly. Let $\theta_{t}=B_{t}^{a} / S_{t}^{a}$ be the ratio of the active buyers to the active sellers, or the tightness of the market, where high $\theta_{t}$ corresponds to a hot (tight) market and low $\theta_{t}$ to a cold (slack) market.

\subsubsection{The dynamics of the state of the housing market}

The dynamics of tightness are driven by the changes in the number of buyers and sellers. The number of buyers and sellers decrease upon a sale, and increase as the new buyers and sellers enter the market. The new sellers can enter the market by buying the house from the development sector, and the inflow of buyers is fixed and equals $d$.

The state of the housing market in the model is the number of buyers $B_{t}$ and the number of sellers $S_{t}$, where

$$
\begin{gathered}
S_{t+1}=S_{t}+H_{t}-\pi_{t} S_{t}^{a} \\
B_{t+1}=B_{t}+d-\pi_{t} S_{t}^{a}
\end{gathered}
$$

and $H_{t}$ is the inflow of sellers, $S_{t}^{a}$ is the number of sellers who actively search for the buyer, and $\pi_{t}$ is the probability of sale. The term $\pi_{t} S_{t}^{a}$ is the number of sales, by the law of large numbers.

The auction and search models differ in the price determination mechanism that pins down the probability of sale $\pi_{t}$ in equations (8) and the sale price.

\subsubsection{Housing supply}

The supply of new homes is simplified to focus on the price determination mechanism. I assume that construction of a new home takes one period and the marginal cost of new home is linearly increasing in the number of new homes $H_{t}, M C\left(H_{t}\right)=c^{h}+\psi H_{t}$, as in Glaeser, Gyourko, and Saiz (2008)

\footnotetext{
${ }^{4}$ The increasing marginal cost represents presence of the scarce production inputs. For example, the supply of land $T$ is fixed. There are infinitely many perfectly competitive identical firms indexed by $i$ with the constant return production technology $H_{i t}=F\left(L_{i t}, T_{i t}\right)$ for producing $H_{i t}$ homes from labor $L_{i t}$ and land $T_{i t}$. The labor market is competitive with wage $p_{L t}$, price of land is $p_{T t}$ and is determined endogenously. The optimal ratio of
} 


\subsection{Price determination by auction}

In the housing market buyers and sellers play a game each period. The stages of the game are:

1. A buyer (a seller) decides whether to incur search cost $c^{b}\left(c^{s}\right)$ to search in period $t$.

2. The buyer randomly chooses only one seller to visit. The number of the buyers that each seller attracts is distributed as a Poisson random variable with the mean $\theta_{t}$. To motivate of the Poisson distribution, suppose that each buyer is picking a seller at random. Then the number of buyers that visit a particular seller is distributed binomially. When the number of sellers goes to infinity (keeping the ratio of number of buyers to number of seller, $\theta$, constant), the distribution of the buyers that visit a seller is Poisson with the mean equal to the ratio of buyers to sellers by the Poisson limit theorem. 5

3. When the buyer visits the seller, he observes the total number of buyers $N$ that have come to the same seller and draws the match-specific value of housing services $x \in[0, \infty)$ that is distributed with the exponential cumulative distribution function $F(x)=1-e^{-\lambda x}$, where $E x=1 / \lambda$.

4. If there are no buyers, $N=0$, then the seller keeps the house with an option to sell it the next period.

5. If there is at least one buyer, $N \geq 1$, then the seller runs an ascending English auction with the public reservation price $\bar{p}$. In the auction the price starts with the reservation price and increases. If all buyers drop-out at the reservation price, the seller keeps the house. Else the bidders drop-out as the price increases until only one is left. The remaining buyer wins the auction, and pays maximum of the second-to-last drop-out price and the reservation price.

6. The winning buyer and the seller make transfers of the house and payments, and leave the market. The buyers and seller who fail to transact, continue on to the next period. New sellers $h$ with newly constructed houses enter, and fixed number $d$ of buyers arrive.

labor to land for each firm depends on the ratio of prices of inputs, $F_{1}^{\prime}\left(L_{i t}, T_{i t}\right) / F_{2}^{\prime}\left(L_{i t}, T_{i t}\right)=p_{L} / p_{T}$. By the constant returns to scale the marginal products are homogenous of degree zero, hence $F_{1}^{\prime}\left(L_{i t}, T_{i t}\right) / F_{2}^{\prime}\left(L_{i t}, T_{i t}\right)=$ $F_{1}^{\prime}\left(L_{i t} / T_{i t}, 1\right) / F_{2}^{\prime}\left(L_{i t} / T_{i t}, 1\right)=p_{L} / p_{T}$. Hence, $L_{i t}=\delta_{t} T_{i t}$, where $\delta_{t}$ depends on the relative prices of labor and land. Aggregating for the construction sector as a whole $L_{t}=\delta_{t} T_{t}$. The total construction $H_{t}$ is then $H_{t}=\sum_{i=1}^{\infty} H_{i t}=\sum_{i=1}^{\infty} F\left(L_{i t}, T_{i t}\right)=\sum_{i=1}^{\infty} F\left(\frac{L_{i t}}{T_{i t}}, 1\right) T_{i t}=\sum_{i=1}^{\infty} F\left(\delta_{t}, 1\right) T_{i t}=F\left(\delta_{t}, 1\right) T_{t}=F\left(L_{t}, T_{t}\right)$ and the marginal costs $M C\left(H_{t}\right)=p_{L} / F_{1}^{\prime}\left(L_{t}\left(H_{t}, T\right), T\right)$ are increasing in $H_{t}$ and assumed to be linearly increasing in the total construction $M C\left(H_{t}\right)=c^{h}+\psi H_{t}$, which is a linear approximation to an increasing function.

${ }^{5}$ For another motivation of the Poisson distribution for the number of bidders for each home on the market, assume that homes are equally spaced across a given area of land. Suppose that buyers search randomly, so as to be located across the area according to the uniform-intensity spatial Poisson distribution. Each buyer bids on the home nearest to his or her location. Then the total number of buyers bidding on each home would be approximately Poisson distributed, iid across homes, with a mean equal (in the limit as the number of buyers and sellers goes to infinity) to the market-wide ratio $\theta$ of number of buyers to number of sellers. See, for example, Badderley, Barany, Schneider, and Weil (2007). I thank Darrell Duffie for pointing this out. 


\subsubsection{The buyer's problem}

Figure 1 present the timing of the events for the buyer. In the beginning of period $t$ the rent payments are made, then the buyer visits one seller and observes the match value $x$, and the total number $N$ of bidders are revealed to buyers and sellers. The auction then takes place. At the end of the period the interest rate accrues. If the buyer won the auction, in the beginning of the next period the transfer of payments and house ownership occurs.

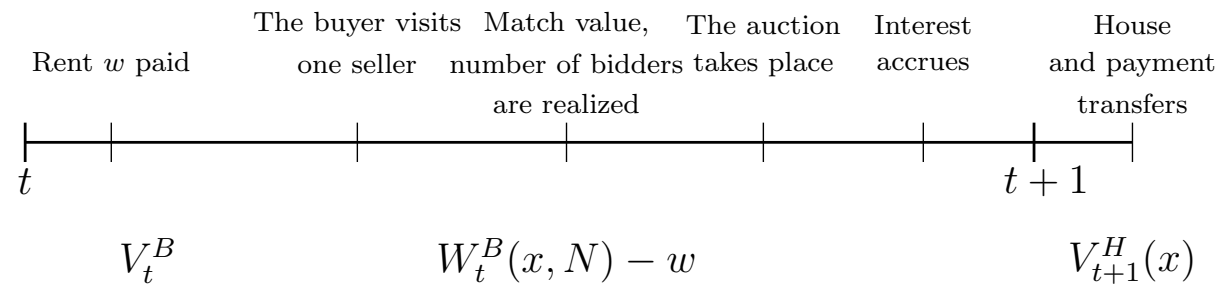

Figure 1: The timeline of the events for the buyer.

If the buyer buys the house with the service flow $x$, his value function as the homeowner is the discounted flow of housing services $V_{t+1}^{H}(x)=\frac{x}{1-\beta}$. The problem of the buyer is then to pick the bid for the house with the match-specific housing services $x$.

The value function of the buyer in period $t$ is $V_{t}^{B}$ before the buyer visits the seller. After the buyer visits the seller, the interim value function of the buyer is $W_{t}^{B}(x, N)$, a function of the match-specific value of housing services $x$ and the total number of buyers $N$ bidding on the house. Then the value function of the buyer in the beginning of the period $V_{t}^{B}$ is the expectation of the value given $x$ and $N$, conditional on the total number of buyers being greater or equal than one, since there is at least the buyer himself

$$
V_{t}^{B}=\max \left\{E_{x, N \geq 1} W_{t}^{B}(x, N)-c_{b}, \beta V_{t+1}^{B}\right\}-w
$$

where $w$ is the per-period rental rate.

Consider an example with the seller and two buyers $N=2$ with bids $b_{1}$ and $b_{2}$ to see how to determine the value of the buyer $W_{t}^{B}(x, N)$, given the realization of the match-specific value $x$ and the total number of buyers $N$. The problem of the first buyer is to pick the bid $b_{1}$ that maximizes his value $W_{t}^{B}(x, N)$. There are three possible outcomes for the first buyer depending on the bid of the second buyer $b_{2}$, see Figure 2. If the second buyer's drop-out price is higher than the first buyer's drop-out price, $b_{2}>b_{1}$, then the first buyer loses. If the second buyer drops out at a price that is below the reservation price of the seller, $b_{2}<\bar{p}$, then the first buyer wins the auction and pays the reservation price $\bar{p}$. If the second buyer has a drop-out price that is higher than the reservation price but lower than the bid of the first buyer, $\bar{p}<b_{2}<b_{1}$, the first buyer wins and pays the price equal to the second bidder's drop-out price, the second-order statistic of the bids $b_{(2)}$. 


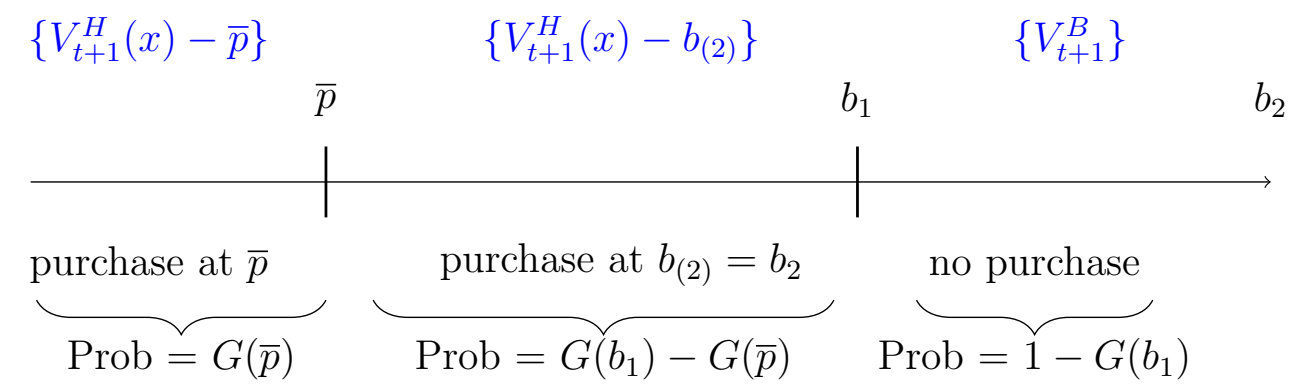

Figure 2: Events for the first buyer with the bid $b_{1}>\bar{p}$. The continuation values are in curly blue brackets.

Let $G($.$) be the equilibrium distribution of the drop-out price for the second buyer, then the$ probabilities of the these events are $G(\bar{p}), G\left(b_{1}\right)-G(\bar{p})$ and $1-G\left(b_{1}\right)$, and the corresponding continuation value functions for the buyer are $V_{t+1}^{H}(x)-\bar{p}, V_{t+1}^{H}(x)-b_{(2)}$ and $V_{t+1}^{B}$.

The same logic can be applied to the case with the total number of buyers $N$ with the symmetric stationary equilibrium strategies $G($.$) . The problem of the buyer is to choose the bid$ that maximizes his continuation value $W_{t}^{B}(x, N)$, which is

$$
W_{t}^{B}(x, N)=\max _{b_{t}} \begin{cases}\beta\left[\left(1-G\left(b_{t}\right)^{N-1}\right) V_{t+1}^{B}+\right. \\ +\left(G\left(b_{t}\right)^{N-1}-G\left(\bar{p}_{t}\right)^{N-1}\right) \int_{\bar{p}_{t}}^{b_{t}} \frac{\left(V_{t+1}^{H}(x)-b_{(2), t}\right)}{\left(G\left(b_{t}\right)^{N-1}-G\left(\bar{p}_{t}\right)^{N-1}\right)} d G\left(b_{(2), t}\right)^{N-1} & \\ \left.+G\left(\bar{p}_{t}\right)^{N-1}\left(V_{t+1}^{H}(x)-\bar{p}_{t}\right)\right] & \text { if } b_{t} \geq \bar{p}_{t} \\ \beta V_{t+1}^{B} & \text { if } b_{t}<\bar{p}_{t}\end{cases}
$$

Because the match-specific housing services $x$ of different buyers are independent, in the ascending auction the dominating strategy for each buyer is to drop-out at his own value $b_{t}$ for the house. In other words, this auction is a Vickrey auction.

When the buyer decides to drop-out at his own value, he compares the continuation value of living in the house starting the next period and paying his value, $V_{t+1}^{H}(x)-b_{t}$, and the continuation value of the buyer for the next period $V_{t+1}^{B}$. The buyer is indifferent when $b_{t}=V_{t+1}^{H}(x)-V_{t+1}^{B}$, which is the maximum value the buyer is willing to pay for the house with the match-specific value $x$, and also the dominant strategy for the buyer.

\subsubsection{The seller's problem}

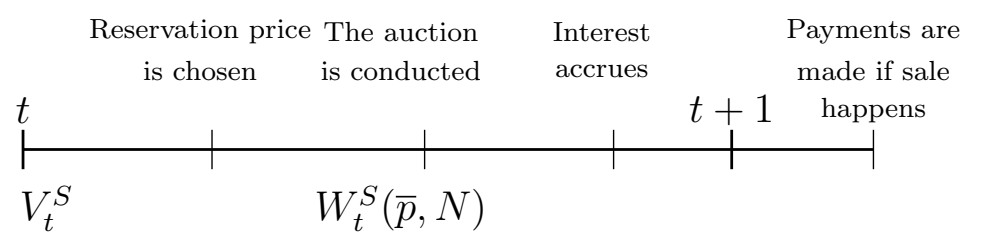

Figure 3: The timeline of the events for the seller. 
Figure 3 shows the timeline for an existing seller. First, the seller picks the reservation price, then buyers arrive and the auction happens. At the end of the period interest accrues, and if the house was sold, payment is made at the beginning of the next period.

The seller's problem is to determine the reservation price. Let the value function of the seller at the beginning of the period be $V_{t}^{S}$, and the interim value function be $W_{t}^{S}(p, N)$, where the total number $N$ of buyers that arrived at the seller's place is known. These value functions must satisfy the Bellman equation

$$
V_{t}^{S}=\max \left\{\max _{\bar{p}} E_{N} W_{t}^{S}(\bar{p}, N)-c^{s}, \beta V_{t+1}^{S}\right\}
$$

Calculation of the seller's value function $W_{t}^{S}(\bar{p}, N)$ is similar to the computation of the buyer's interim value function. Consider the example with the seller and two buyers $(N=2)$ with the drop-out prices $b_{1}$ and $b_{2}$. There are three possible cases for the seller, as shown in Figure 4. In case 1 both buyers drop-out at a price lower than the reservation price, hence there is no sale, and the seller's continuation value is $V_{t+1}^{S}$. In case 2 the drop-out price of one buyers is lower than the reservation price, but the drop-out price of the other buyer is higher than the reservation price. Then there is a sale at the reservation price, which is the payoff of the seller. Lastly, in case 3, the drop-out prices of both buyers are higher than the reservation price of the seller, and the sale closes at the second highest drop-out price $b_{(2)}$. The corresponding probabilities are $G^{2}(p)$ (no sale), $2 G(\bar{p})(1-G(\bar{p}))$ (sale at the reservation price), and $(1-G(\bar{p}))^{2}$ (sale at the second-order statistic of the drop-out prices $\left.b_{(2)}\right)$.

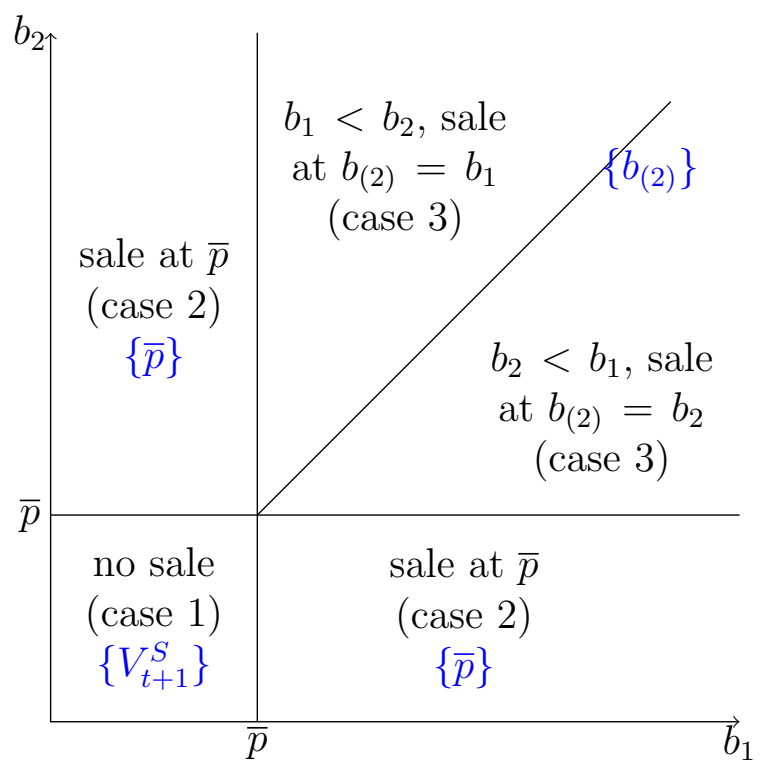

Figure 4: The auction outcomes for a seller with two buyers. The continuation values are in curly blue brackets.

The general case with $N$ buyers is considered similarly, and the interim value function of the 
seller is

$$
W_{t}^{S}\left(\bar{p}_{t}, N\right)=\beta\left[G\left(\bar{p}_{t}\right)^{N} V_{t+1}^{S}+N G\left(\bar{p}_{t}\right)^{N-1}\left(1-G\left(\bar{p}_{t}\right)\right) \bar{p}_{t}+M\left(\bar{p}_{t}, N\right) \int_{\bar{p}_{t}}^{\infty} y \frac{m(y, N)}{M\left(\bar{p}_{t}, N\right)} d y\right]
$$

where the cumulative distribution function of the second order statistic is $M(y, N)=1-$ $N G(y)^{N-1}(1-G(y))-G(y)^{N}$ if $y \geq \bar{p}_{t}$ and zero otherwise, and $m(y, N)=-\partial M(y, N) / \partial y$. Taking into account that $\beta(1+r)=1$ and simplifying, (6) can be rewritten as

$$
W_{t}^{S}\left(\bar{p}_{t}, N\right)=\beta\left(G\left(\bar{p}_{t}\right)^{N} V_{t+1}^{S}+N G\left(\bar{p}_{t}\right)^{N-1}\left(1-G\left(\bar{p}_{t}\right)\right) \bar{p}_{t}+\int_{\bar{p}_{t}}^{\infty} y m(y, N) d y\right)
$$

\subsubsection{Equilibrium}

The state of the economy is a triple $\mathcal{S}_{t}=\left(B_{t}, S_{t}, z_{t}\right)$, where $B_{t}$ is the number of buyers, $S_{t}$ is the number of sellers, and $z_{t}$ is the state for the aggregate shock to parameters of the model, such as the discount factor $\beta$.

Definition 1. For given values $B_{0}, S_{0}, z_{0}$, a discrete-time perfect foresight stationary equilibrium is a set of time-invariant value functions $V_{t}^{B}=V^{B}\left(\mathcal{S}_{t}\right), W_{t}^{B}(x, N)=W^{B}\left(\mathcal{S}_{t} \mid x, N\right)$ for the buyer and $V_{t}^{S}=V^{S}\left(\mathcal{S}_{t}\right), W_{t}^{S}(\bar{p}, N)=W^{S}\left(\mathcal{S}_{t} \mid \bar{p}, N\right)$ for the seller, and a set of policy functions $b_{t}(x)=b\left(\mathcal{S}_{t} \mid x\right)$ for the buyer and $\bar{p}_{t}=\bar{p}\left(\mathcal{S}_{t}\right)$ for the seller, the inflow of sellers $H_{t}\left(\mathcal{S}_{t}\right)$ and a law of motion $\mathcal{S}_{t+1}=\Gamma\left(\mathcal{S}_{t}\right)$ such that

1. The value functions $V_{t}^{B}, W_{t}^{B}(x, N), V_{t}^{S}, W_{t}^{S}(\bar{p}, N)$ satisfy the Bellman equations (3), (6), (15), (7), correspondingly

2. Buyers follow the weakly dominated strategy $b_{t}(x)$

3. Sellers choose the optimal reservation price $\bar{p}_{t}$

4. The market for newly supplied homes clears

5. The law of motion for the state is consistent with the individual behavior:

$$
\begin{aligned}
S_{t+1} & =S_{t}+H_{t}-\pi_{t} S_{t}^{a} \\
B_{t+1} & =B_{t}+d-\pi_{t} S_{t}^{a} \\
z_{t+1} & =\rho z_{t}+\varepsilon_{t}
\end{aligned}
$$

6. $\lim _{t \rightarrow \infty} V_{t}^{B}, \lim _{t \rightarrow \infty} W_{t}^{B}(x, N), \lim _{t \rightarrow \infty} V_{t}^{S}, \lim _{t \rightarrow \infty} W_{t}^{S}(\bar{p}, N)$ are finite.

Define the threshold match-specific value $\bar{x}_{t}$ such that the equilibrium bid equals the reservation price of the seller $\bar{p}_{t}$, that is $b_{t}\left(\bar{x}_{t}\right)=\bar{p}_{t}$.

Proposition 1 (Auction model). The optimal bid is the present value for the house less the option value to buy the next period $b_{t}(x)=\frac{x}{1-\beta}-V_{t+1}^{B}$. The optimal reservation price is the value to sell the next period plus the expected present value of the housing services $\bar{p}_{t}=V_{t+1}^{S}+\frac{1}{\lambda(1-\beta)}$. The price for the newly built house is $\beta V_{t+1}^{S}$, and the inflow of new sellers is $H_{t}=\frac{\beta V_{t+1}^{S}-c^{h}}{\psi}$. 
Proof. The dominant strategy in the ascending bid auction is the value of the object. The value of the house for a buyer is what he will get living in the house, the present value of housing services $\frac{x}{1-\beta}$, net of what he will lose by purchasing the house, which is the option value to buy tomorrow, $V_{t+1}^{B}$. The value of buying a house for a buyer is $\left.v_{t}(x)=\frac{x}{1-\beta}-V_{t+1}^{B}\right)$. Hence, each buyer bids $b_{t}(x)=\frac{x}{1-\beta}-V_{t+1}^{B}$.

The seller sets the optimal reservation price by equalizing his value of the house, which is the option value to sell, $V_{t+1}^{S}$ to the marginal revenue from the buyer ${ }^{6}$. The marginal revenue from the buyer, or the virtual value, is $\tilde{v}(x)=v(x)-\frac{1-F(v(x))}{f(v(x))}=\frac{x}{1-\beta}-V_{t+1}^{B}-\frac{E x}{1-\beta}$. Hence, the optimal reservation value of housing services $\bar{x}_{t}$ is $\frac{\bar{x}}{1-\beta}-V_{t+1}^{B}-\frac{E x}{1-\beta}=V_{t+1}^{S}$, or $\bar{x}=E x+(1-\beta)\left(V_{t+1}^{B}+V_{t+1}^{S}\right.$, and the corresponding optimal reservation price is $\bar{p}=b_{t}\left(\bar{x}_{t}\right)=V_{t+1}^{S}+\frac{E x}{1-\beta}$.

See also appendix A.1

Proposition 2 (Auction model). The value functions of the buyer and the seller are solutions to

$$
\begin{aligned}
V_{t}^{S} & =\beta V_{t+1}^{S}+\max \left\{\frac{\beta \varphi\left(\theta_{t} e^{-\lambda \bar{x}_{t}}\right)}{\lambda(1-\beta)}-c^{s}, 0\right\} \\
V_{t}^{B} & =\beta V_{t+1}^{B}+\max \left\{\frac{\beta \pi\left(\bar{x}_{t}, \theta_{t}\right)}{\lambda(1-\beta) \theta_{t}}-c^{b}, 0\right\}-w
\end{aligned}
$$

where the probability of sale $\pi_{t}$ is $\pi_{t}=\pi\left(\bar{x}_{t}, \theta_{t}\right)=1-\exp \left(-\theta_{t} \exp \left(-\lambda \bar{x}_{t}\right)\right)$, the increasing and concave function $\varphi($.$) is defined as \varphi\left(\theta_{t}\left(1-F\left(\bar{x}_{t}\right)\right)\right)=\int_{0}^{\theta_{t}\left(1-F\left(\bar{x}_{t}\right)\right)} \frac{1-e^{-y}}{y} d y=\lambda \int_{\bar{x}_{t}}^{\infty} \pi\left(x, \theta_{t}\right) d x$, and the tightness $\theta_{t}=B_{t}^{a} / S_{t}^{a} \geq 0$ is such that $\frac{\beta \varphi\left(\theta_{t} e^{\left.-\lambda \bar{x}_{t}\right)}\right.}{\lambda(1-\beta)}-c^{s} \geq 0$ and $\frac{\beta \pi\left(\bar{x}_{t}, \theta_{t}\right)}{\lambda(1-\beta) \theta_{t}}-c^{b} \geq 0$ with complementary slackness. The expected house price is

$$
\hat{p}_{t}=V_{t+1}^{S}+\frac{\varphi\left(\theta_{t} e^{-\lambda \bar{x}_{t}}\right)}{\lambda(1-\beta) \pi\left(\bar{x}_{t}, \theta_{t}\right)}=V_{t+1}^{S}+\frac{\int_{\bar{x}_{t}}^{\infty} \pi\left(x, \theta_{t}\right) d x}{(1-\beta) \pi\left(\bar{x}_{t}, \theta_{t}\right)}
$$

Proof. The probability that a buyer with value $x$ has highest valuation is $E_{N} F^{N-1}(x)=e^{\theta_{t}(1-F(x))}$, where $N \sim \operatorname{Poisson}\left(\theta_{t}\right)$ is the number of active buyers per active seller. The value function of the buyer is then

$$
\begin{aligned}
V_{t}^{B}= & \max \left\{\beta \int_{\bar{x}_{t}}^{\infty}(v(x)-\tilde{v}(x)) e^{-\theta_{t}(1-F(x))} f(x) d x-c_{b}, 0\right\}+ \\
& +\beta V_{t+1}^{B}-w=\beta V_{t+1}^{B}+\max \left\{\beta \frac{\pi\left(\bar{x}_{t}, \theta_{t}\right)}{\lambda(1-\beta) \theta_{t}}-c_{b}, 0\right\}-w
\end{aligned}
$$

where $\frac{\pi\left(\bar{x}_{t}, \theta_{t}\right)}{\lambda(1-\beta) \theta_{t}}$ is the information rent of the buyer from the auction due to private information about the value of the house.

Similarly, the value function of the seller is

$$
\begin{array}{r}
V_{t}^{S}=\max \left\{\theta \int_{\bar{x}_{t}}^{\infty}\left(\tilde{v}(x)-V_{t+1}^{S}\right) e^{-\theta_{t}(1-F(x))} f(x) d x-c^{s}, 0\right\}+\beta V_{t+1}^{S}= \\
=\beta V_{t+1}^{S}+\max \left\{\beta \frac{\int_{\bar{x}_{t}}^{\infty} \pi\left(x, \theta_{t}\right) d x}{(1-\beta)}-c^{s}, 0\right\}=\beta V_{t+1}^{S}+\max \left\{\beta \frac{\varphi\left(\theta_{t} e^{-\lambda \bar{x}_{t}}\right)}{\lambda(1-\beta)}-c^{s}, 0\right\}
\end{array}
$$

\footnotetext{
6 Bulow and Roberts (1989)
} 
where $\frac{\varphi\left(\theta_{t} e^{-\lambda \bar{x}_{t}}\right)}{\lambda(1-\beta)}$ is the expected revenue of the seller.

See also appendix A.1

\subsection{Price determination by Nash bargaining}

The goal is to compare the implications of the search model with an auction from section 3.2 to the benchmark search model with Nash bargaining. This subsection describes how the price is determined via Nash bargaining. The buyers are searching for the sellers, and the number of meetings is described by the matching function. After the meeting, a random buyer matched to the seller is chosen, after that the buyer and the seller negotiate, and the price splits the benefits from the trade.

The models are made as similar as possible to study how predictions of the models differ depending on which price determination mechanism is used. In particular, to match the meeting probabilities in both models, I use the urn-ball meeting function $M\left(B_{t}^{a}, S_{t}^{a}\right)=S_{t}^{a}\left(1-\left(1-\frac{1}{S_{t}^{a}}\right)^{B_{t}^{a}}\right)$. The urn-ball meeting function gives the number of meetings $M$ from the stocks of active buyers $B_{t}^{a}$ and active sellers $S_{t}^{a}$. This number of meetings occurs if buyers reach out to sellers and, if the seller gets more than one buyer, she selects the buyer at random. If the number of buyers and sellers is large, the matching function is well approximated by

$$
M\left(B_{t}^{a}, S_{t}^{a}\right)=S_{t}^{a}\left(1-\exp \left(-B_{t}^{a} / S_{t}^{a}\right)\right)=S_{t}^{a}\left(1-\exp \left(-\theta_{t}\right)\right)
$$

The probability of meeting a buyer to a seller is $q^{s}\left(\theta_{t}\right)=1-\exp \left(-\theta_{t}\right)$, which is the same as the probability of a seller meeting at least one buyer in the auction model $P(N=1)=1-\exp \left(-\theta_{t}\right)$ due to the Poisson distribution of the buyers. For a seller, the probability of meeting a buyer is then $q^{b}\left(\theta_{t}\right)=\left(1-\exp \left(-\theta_{t}\right)\right) / \theta_{t}$.

The key difference of the Nash bargaining model from the auction model is the process of price determination. In the Nash bargaining model, the price is determined using the Nash bargaining solution where sellers and buyers meet and bargain over the price. Following a standard search model, such as that of Genesove and Han (2012), the transaction occurs only if the joint surplus from the sale is positive. The transaction price is the one that splits the joint surplus between the buyer and seller according to their bargaining powers. In particular, the joint surplus from the sale is $\frac{x}{1-\beta}-V_{t+1}^{S}-V_{t+1}^{B}$. Hence the buyer and the seller transact if $x \geq \bar{x}_{t}=(1-\beta)\left(V_{t+1}^{S}+V_{t+1}^{B}\right)$ at a price that is determined via Nash bargaining $]^{7} p_{t}=V_{t+1}^{S}+\alpha\left(\frac{x}{1-\beta}-V_{t+1}^{S}-V_{t+1}^{B}\right)$. The expected house price ${ }^{8}$ is then

$$
p_{t}=V_{t+1}^{S}+\alpha\left(\frac{E\left[x \mid x \geq \bar{x}_{t}\right]}{1-\beta}-V_{t+1}^{S}-V_{t+1}^{B}\right)=V_{t+1}^{S}+\frac{\alpha}{\lambda(1-\beta)}
$$

Let $q^{d}\left(\bar{x}_{t}\right)=1-F\left(\bar{x}_{t}\right)=e^{-\lambda \bar{x}_{t}}$ be the probability of sale or deal conditional on the buyer and seller meeting. The probability of sale in the search model is then $\pi\left(\bar{x}_{t}, \theta_{t}\right)=q^{s}\left(\theta_{t}\right) q^{d}\left(\bar{x}_{t}\right)=$ $\left(1-e^{-\theta_{t}}\right) e^{-\lambda \bar{x}_{t}}$.

\footnotetext{
${ }^{7}$ The buyer's surplus is $B S_{t}=\beta\left(\frac{x}{1-\beta}-V_{t+1}^{B}-p_{t}\right)$, the seller's surplus is $S S_{t}=\beta\left(p_{t}-V_{t+1}^{S}\right)$, and the price maximizes the weighted product of the surpluses $S S_{t}^{\alpha} B S_{t}^{1-\alpha}$, FOC is $S S_{t}=\alpha\left(B S_{t}+S S_{t}\right)$ or $p_{t}-V_{t+1}^{S}=$ $\alpha\left(x /(1-\beta)-V_{t+1}^{B}-p_{t}+p_{t}-V_{t+1}^{S}\right)$

${ }^{8} E[x \mid x \geq \bar{x}]=\bar{x}+\frac{1}{\lambda}$ simplifies due to the memoryless property of the exponential distribution
} 
Proposition 3 (Nash bargaining model). The seller's and buyer's value functions satisfy

$$
\begin{aligned}
V_{t}^{S} & =\beta V_{t+1}^{S}+\max \left\{\beta \pi\left(\bar{x}_{t}, \theta_{t}\right)\left(\frac{\alpha}{\lambda(1-\beta)}-V_{t+1}^{S}\right)-c^{s}, 0\right\} \\
V_{t}^{B} & =\beta V_{t+1}^{B}+\max \left\{\beta \frac{\pi\left(\bar{x}_{t}, \theta_{t}\right)}{\theta_{t}}\left(\frac{1-\alpha}{\lambda(1-\beta)}-V_{t+1}^{B}\right)-c^{b}, 0\right\}-w
\end{aligned}
$$

and the tightness $\theta_{t}=B_{t}^{a} / S_{t}^{a} \geq 0$ is such that $\beta \pi\left(\bar{x}_{t}, \theta_{t}\right)\left(\frac{\alpha}{\lambda(1-\beta)}-V_{t+1}^{S}\right)-c^{s} \geq 0$ and $\beta \frac{\pi\left(\bar{x}_{t}, \theta_{t}\right)}{\theta_{t}}\left(\frac{1-\alpha}{\lambda(1-\beta)}-\right.$ $\left.V_{t+1}^{B}\right)-c^{b} \geq 0$ with complementary slackness. The inflow of new sellers is $H_{t}=\frac{\beta V_{t+1}^{S}-c^{h}}{\psi}$.

\subsection{Comparison of the auction and Nash bargaining models}

As noted in the previous section, the key difference between two models is the process of price determination, where in the auction model the expected prices are

$$
\hat{p}_{t}=V_{t+1}^{S}+\frac{\varphi\left(\theta_{t}\left(1-F\left(\bar{x}_{t}\right)\right)\right)}{\pi\left(\bar{x}_{t}, \theta_{t}\right)} P V_{x}
$$

and in the Nash bargaining model

$$
\hat{p}_{t}=V_{t+1}^{S}+\alpha P V_{x}
$$

where $P V_{x}=\frac{1}{\lambda(1-\beta)}=\frac{E x}{(1-\beta)}$ is the discounted expected present value of housing services $x$. In both models a seller is compensated for the option to sell $V_{t+1}^{S}$. In addition to the option value to sell, in the Nash bargaining model a seller gets fraction equal to the seller's bargaining power $\alpha \in(0,1)$ of the discounted expected present value of the housing services. By contrast, in the auction model, the seller gets the discounted present value of the housing services, multiplied by the premium $\frac{\varphi\left(\theta_{t}\left(1-F\left(\bar{x}_{t}\right)\right)\right)}{\pi\left(\bar{x}_{t}, \theta_{t}\right)}$, which is bigger than one by lemma 1 in appendix A.1. Note that the premium $\frac{\varphi\left(\theta_{t}\left(1-F\left(\bar{x}_{t}\right)\right)\right)}{\pi\left(\bar{x}_{t}, \theta_{t}\right)} \geq 1$ and the bargaining power $\alpha \in[0,1]$. Thus, even if the option values to sell the next period are the same in two models, the expected prices are higher in the auction model. The option values to sell are same in the steady state of the two models. However, outside of the steady state the option value to sell is the expected discounted sum of the future expected revenues, and hence will capitalize the expected future revenues from the sale. Because the level of expected prices and probability of sale differ across two models, the option values to sell will be different as well.

\section{Steady state}

Proposition 4 compares the steady states of the auction and Nash bargaining models. In the steady state the comparison of prices simplifies, because the value function of the seller is the same in both models in steady state by Proposition 4. The value functions of the seller are equal in the two models, because the inflow of sellers not only has to be the same but also equal to the inflow of buyers to make the number of sellers and buyers constant in the state dynamics (8). With the fixed and equal option value to sell in (20) and (21), the prices in the auction model are higher than in the Nash bargaining model. 
Proposition 4 (Comparison of steady-states in auction and Nash bargaining models). Given the same parameters of the model in the steady state

1. The construction $H$, sales and value of the seller $V^{S}$ are the same in both models.

2. The expected house price is higher in the auction model than in the Nash bargaining model.

3. The probability of sale $\pi$ is lower in the auction model than in the Nash bargaining model.

4. The number of sellers $S$ is greater in the auction model compared to the Nash bargaining model.

5. The buyer's value function $V^{B}$ is higher in the auction model than in the Nash bargaining model.

6. The threshold match-specific value $\bar{x}$ is higher in the auction model than in the Nash bargaining model.

Proof. See appendix A.1

Time on the market for seller - the inverse of the probability of sale - is a commonly used measure of liquidity of the housing market. In the steady state the probability of sale is lower in the auction model, meaning it takes longer to sell the house. Because the prices are higher in the auction model but the option values to sell are the same, the auction model has longer selling times and more sellers lingering on the market.

\section{Quantitative analysis}

\subsection{Calibration}

Table 1 summarized the calibration of parameters of the auction model and the Nash bargaining model. The two models share 8 parameters. The Nash bargaining model has the bargaining power of the seller $\alpha$ as an additional parameter. The bargaining power of the seller $\alpha$ in the model with Nash bargaining is calibrated to be equal to the share of expected surplus of the seller in the total expected surplus in the auction model, 0.68.

The period in the model is taken to be a month. The discount factor $\beta$ is 0.93 , or the discount rate $\$ 7.53 \%$, per annum based on Carrillo (2012). The inflow of new buyers $d$ equals the sales in the steady state of both models, and is calibrated to the average sales from June 2008 to July 2015 in Los Angeles, CA, based on Zillow datd?

The rent $w$ and the expectation of the match-specific housing services $x, 1 / \lambda$, are set equal to the average monthly real rent from 1968 to 2015. The data on nominal rent comes from the Lincoln Institute of Land Policy ${ }^{10}$, see Davis, Lehnert, and Martin (2008), and is based on the U.S. Bureau of Labor Statistics (BLS) owner-equivalent rent after 2012 and tenant rent before

9 Www.zillow.com/research/data

10 http://www.lincolninst.edu/subcenters/land-values/rent-price-ratio.asp 
2012. The nominal rent was deflated by CPI from the BLS11 with CPI set to 100 in the first quarter of 2015. Thus all prices are in 2015:Q1 dollars.

The seller's and buyer's search costs $c^{s}, c^{b}$, similar to Guren (2014), are set to $\$ 10 \mathrm{k}$. Gyourko and Saiz (2004) report average cost per square feet in 2003 in 2000 year dollars as $\$ 57.92$ per median size 1,704 sq. (American Housing Survey) detached home, which is $\$ 72,000$ in 2013 dollars. The level of the marginal costs $c^{h}$ and the slope parameter $\psi$ are chosen such that the construction costs vary from the $\$ 60,000$ in the cold market, which is lower than the estimates in the literature, and to $\$ 1,014,000$, which is close to the values in Glaeser and Gyourko (2003). The implied elasticity of housing supply with respect to house prices in the steady state of the auction model is 3.9 and of the Nash bargaining model is 2.98. Both are close to 3.7, estimated by Green, Malpezzi, and Mayo (2005) for the Los Angeles metropolitan statistical area.

Table 1: Calibration

\begin{tabular}{l|c|c|c}
\hline \hline Parameter & Symbol & Value & Matched moment/Reference \\
\hline \hline period & & month & \\
inflow of new buyers & $d$ & 8000 & mean sales in Los Angeles, CA, Zillow \\
discount rate & $\beta$ & $0.93^{1 / 12}=0.99$ & Carrillo (2012) \\
rent & $w$ & $\$ 798$ & mean real rent \\
mean match value & $1 / \lambda$ & $\$ 798$ & mean real rent \\
seller's search costs & $c^{s}$ & $\$ 10,000$ & Guren $(2014)$ \\
buyers's search costs & $c^{b}$ & $\$ 10,000$ & Guren $(2014)$ \\
housing supply $M C$ level & $c^{h}$ & $\$ 10,000$ & construction costs $\$ 60,000-104,300$ per unit \\
housing supply $M C$ angle & $\psi$ & $\$ 50,000 / 8000=\$ 6.25$ & share of surplus of seller in auction model \\
bargaining power of seller & $\alpha$ & 0.68 & . \\
\hline
\end{tabular}

This table summarizes the calibration of parameters of the auction model and Nash bargaining model. Dollar values are real, in prices of 2015:Q1.

\subsection{Comparison of steady states}

Proposition 4 provides a comparison of the prices, probability of sale, the number of buyers and sellers in steady states of two models. How big are these differences? Table 3 show the comparison of the steady-state values in two models. The prices in the auction model are 30 percent higher than in the Nash bargaining model. The housing is less liquid in the auction model: the probability of sale is five times lower and, on the flip side, it takes at least four times longer to sell or buy a house. If the market size is measured as the number of buyer and sellers, then the market size is four times bigger in the auction model than in the Nash bargaining model.

${ }^{11}$ FRED https://research.stlouisfed.org/fred2/series/CPIAUCSL 
Table 2: Steady-state values in the auction and Nash bargaining models

\begin{tabular}{|c|c|c|c|}
\hline & Auction & Proposition $[4]$ & "Nash bargaining \\
\hline Expected prices $\hat{p}$, thousand $\$$ & 195 & $>$ & 149 \\
\hline Probability of sale $\pi(\bar{x}, \theta), \%$ & 7.7 & $<$ & 35 \\
\hline Number of sellers $S$, thousands & 103 & $>$ & 22 \\
\hline Number of buyers $B$, thousands & 91 & & 22 \\
\hline Tightness $\theta=B / S$ & 0.88 & & 0.99 \\
\hline Time on the market for seller $T_{s}$, months & 12.9 & $>$ & 2.8 \\
\hline Time on the market for buyer $T_{b}$, months & 11.4 & & 2.7 \\
\hline Option value to sell $V^{S}$, thousand $\$$ & 60 & $=$ & 60 \\
\hline Option value to buy $V^{B}$, thousand $\$$ & 124 & $>$ & 13 \\
\hline Threshold $\bar{x}, \$$ & 1,909 & $>$ & 442 \\
\hline Sales $\pi(\bar{x}, \theta) S^{a}$, thousand units & 8 & $=$ & 8 \\
\hline Inflow of sellers $H$, thousand units & 8 & $=$ & 8 \\
\hline
\end{tabular}

\subsection{Transitional dynamics}

This section explores the differences in reaction of house prices to shocks to the housing market. I consider shocks to the discount factor $\beta$, to the parameter of the expectation of housing services $\lambda$, to the rent $w$ and to the inflow of new buyers $d$. In this section I concentrate on a particularly important shock - the shock of the discount factor $\beta$.

With the shocks to the discount factor, the state of the housing market is now described by the value of the discount factor in addition to the number of buyers and sellers as in the law of motions (8) with shocks to the discount factor $\beta_{t}$. The discount factor follows $A R(1)$ $z_{t}=\rho z_{t-1}+\varepsilon_{t}, \beta_{t}=0.93+0.01 z_{t}$ process where the persistence parameter $\rho$ is taken to be 0.9 per annum. The high value of $\rho$ captures the persistence of shocks to the housing market.

In the dynamic model with the shock the price depending on the state of the housing market in the auction model is presented in Figure 5. The housing market is characterized by the hot market when there are many buyers and small number of sellers and high prices and the cold market with few buyers and many sellers and low prices. The circle marker shows the steadystate. The shocks start the fluctuations of prices between the hot and cold market. 
Figure 5: Prices, in thousands of dollars, depending on the state of housing market in the auction model

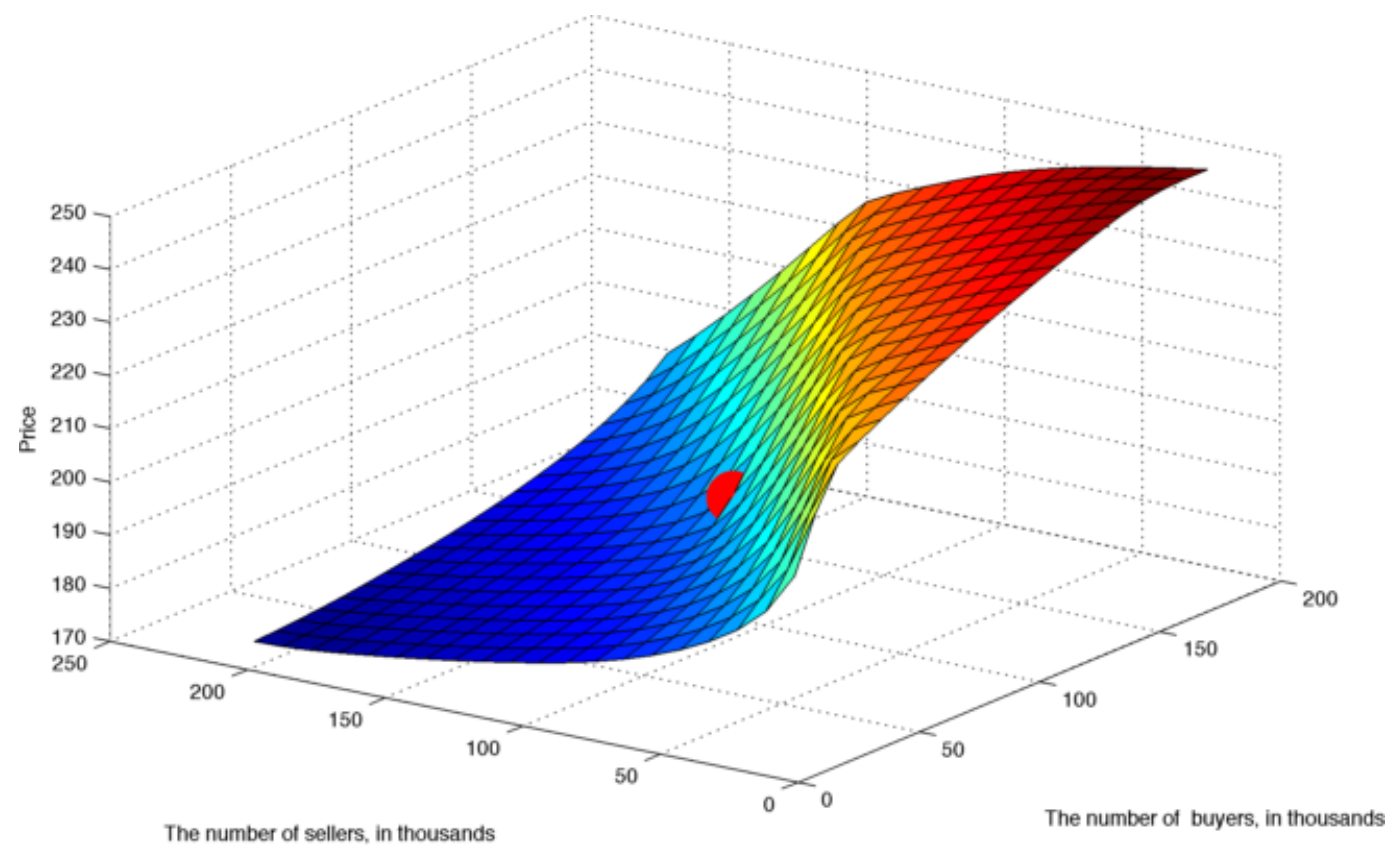

The discount factor follows $A R(1) z_{t}=\rho z_{t-1}+\varepsilon_{t}, \beta_{t}=0.93+0.01 z_{t}$ process. The graph draws prices for $\beta=0.94$.

I study an experiment that highlights how an exogenous increase in the discount factor $\beta$ from 0.93 to 0.94 on annual basis, or alternatively, decrease in the real rate $r=1 / \beta-1$ from $7 \%$ to $6 \%$, affects house prices. The dynamics of the discount factor following the shock is depicted in Figure 6a. 
Figure 6: Dynamics of (a) the discount factor $\beta$ after one-time shock and of (b) difference of price path in model with shock and model without shock

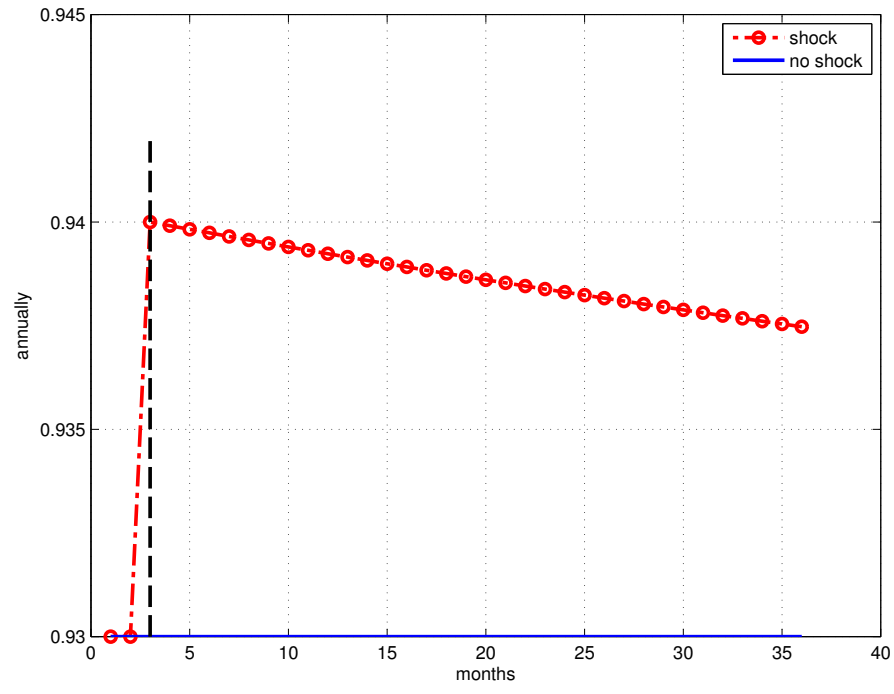

(a) The discount factor $\beta$ shock

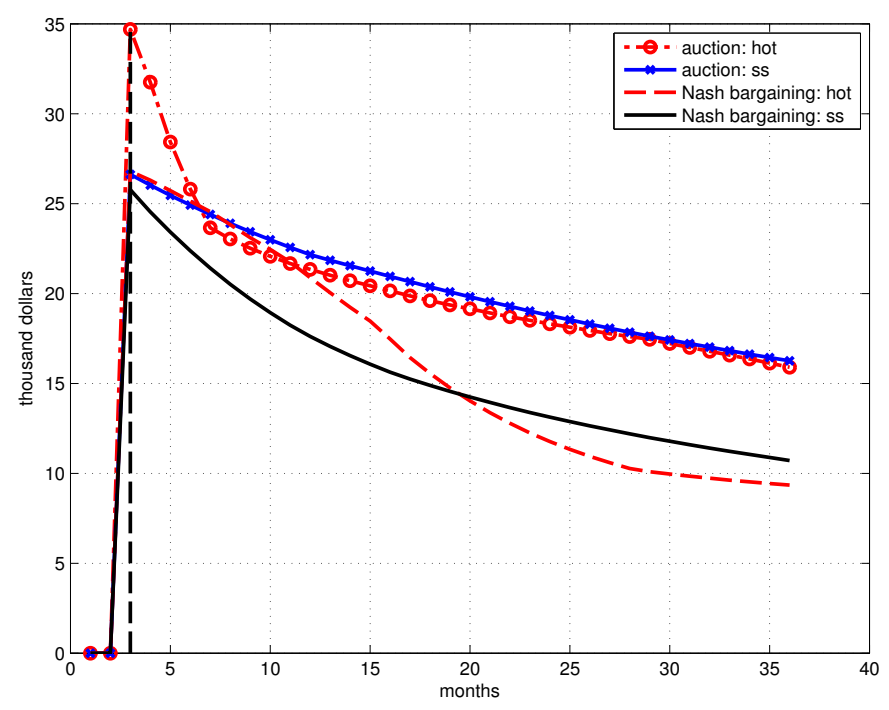

(b) Price paths in model with shock and without shock

In the legend 'hot' stands for hot market (buyers are indifferent between searching and not searching), 'ss' stands for steady state. The discount factor follows $A R(1)$ process.

Figure $6 \mathrm{~b}$ shows how the house prices in the auction model and in Nash bargaining model react to the one-time discount factor shock. The solid black line and solid blue line with crosses show how the prices in the Nash bargaining model and auction model that start from the steady state respond to the discount factor shock. The response of prices in the auction model is greater than in the Nash bargaining model, and the convergence of the prices back to the initial value is slower in the auction model than in the Nash bargaining model.

Second, the dashed red line and the solid blue line with circles show how the house prices react if the housing market is hot. A hot market is defined as one where there are so many buyers that a buyer is indifferent between searching or staying off the market, or, in other words, the participation constraint of the buyer is binding. The hot markets form a subset of the state space of the model, and the figure shows one of the the hot markets, where there are three times more buyers than in there are in the steady-state. The initial increase of house prices is again more pronounced and persistent in the auction model rather than in the Nash bargaining model similar to the predictions of models in the steady-state. Moreover, the house prices shoot up in the hot market of auction model, while the reaction of the house prices in the hot market of Nash bargaining model is similar to that in the steady-state. To summarize, if in the model house prices are determined by an auction rather than by Nash bargaining, then the house prices response to the discount factor shock is larger and more persistent, especially in the hot market. 
Figure 7: The dynamics of the value function of a seller in the hot market of the auction model

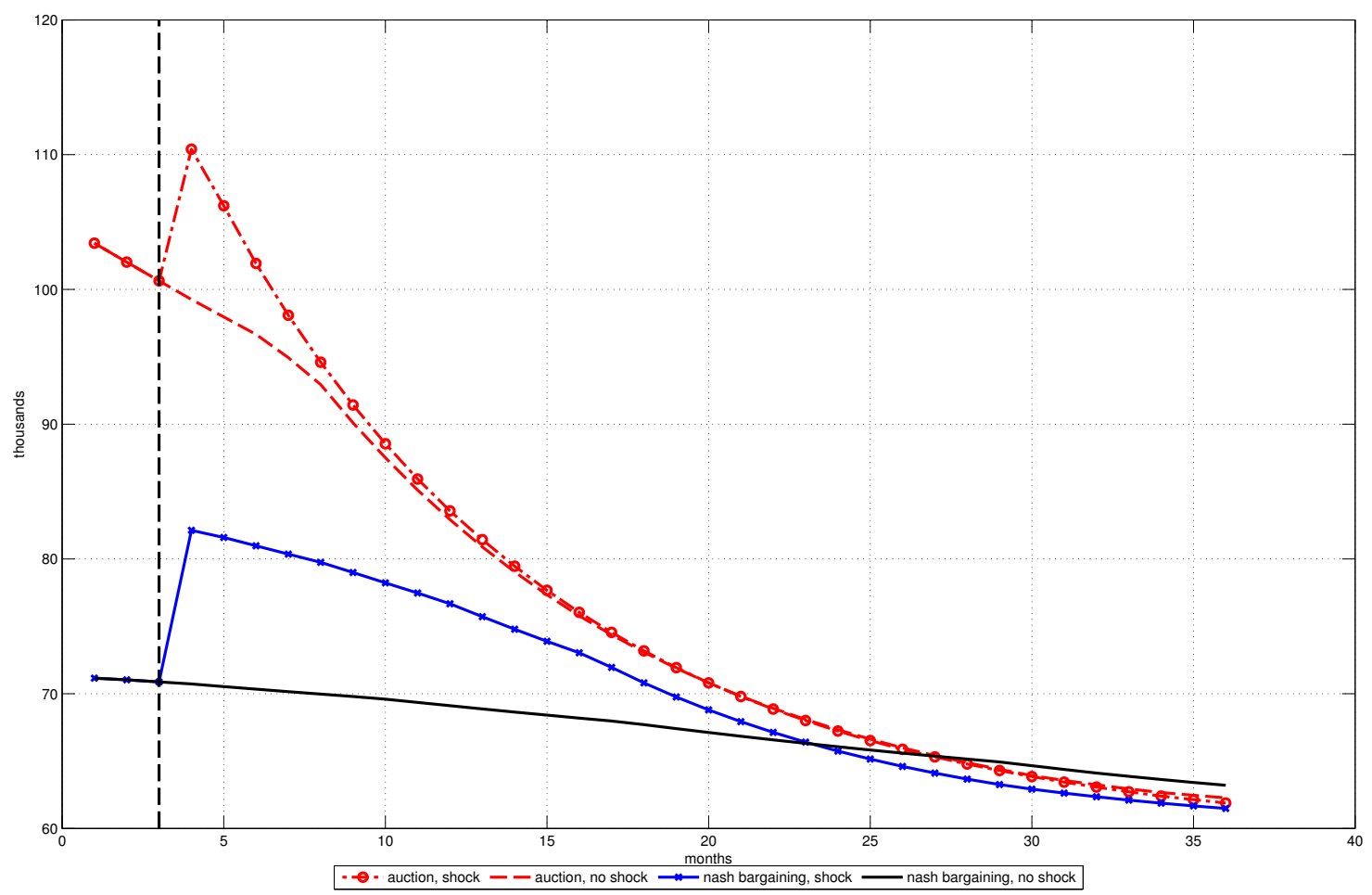

Why do house prices respond more in the auction model, especially if the housing market is hot? The change in prices stems from the change in each of the two terms in (20) and 21) for each model. First, examine the change in the value function of a seller. The increase of the discount factor raises the expected present value of housing services $P V_{x}$, and the option value to sell is the discounted expected revenue minus the cost of selling. Hence, due to increase in the expected discounted present match-specific value $P V_{x}$ the option value to sell $V_{t+1}^{S}$ and option value to buy $V_{t+1}^{B}$ will increase as shown in Figure 7 . The black vertical dashed line shows the time of the shock. The black solid line and the blue line with crosses show the dynamics of the option value to sell in the Nash bargaining model without the shock and with the shock. Similarly, the red dashed line and the red dashed line with circles show the time-series for the value function of the seller in the auction model. The option value to sell increases by around $\$ 11,400$ in the Nash bargaining model, which is close to $\$ 11,145$ for the auction model. 
Figure 8: Number of buyers and sellers in the hot market of the auction model, in thousands

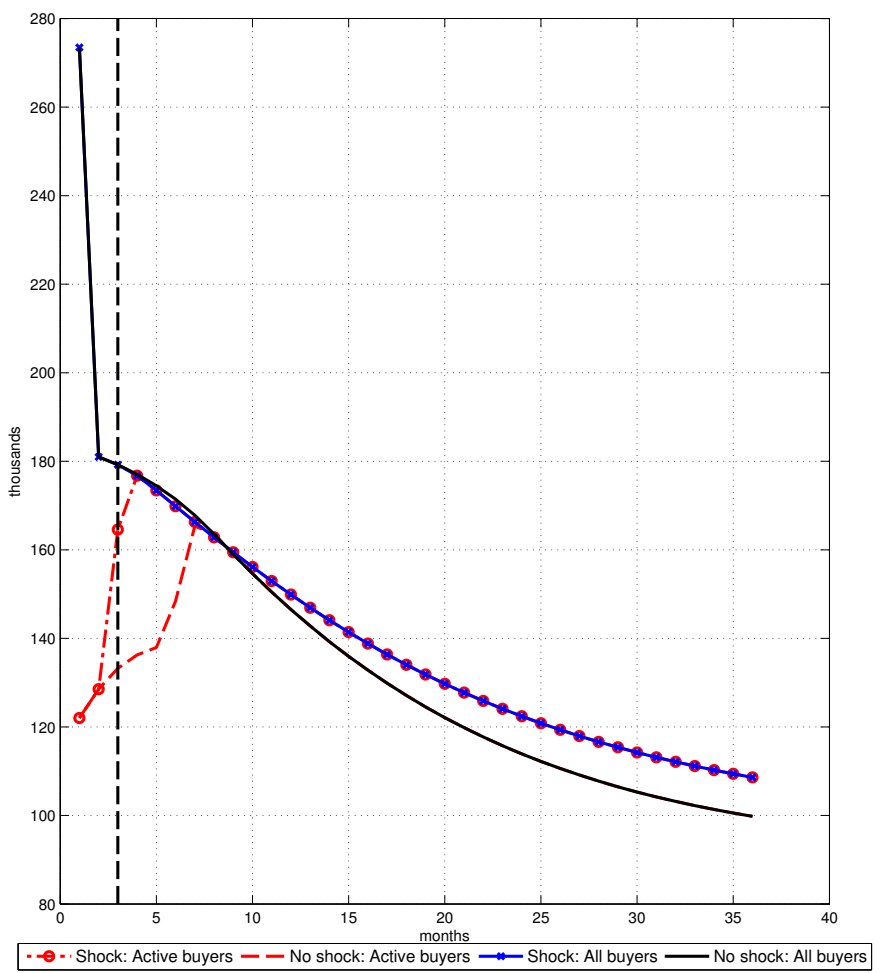

(a) Number of buyers

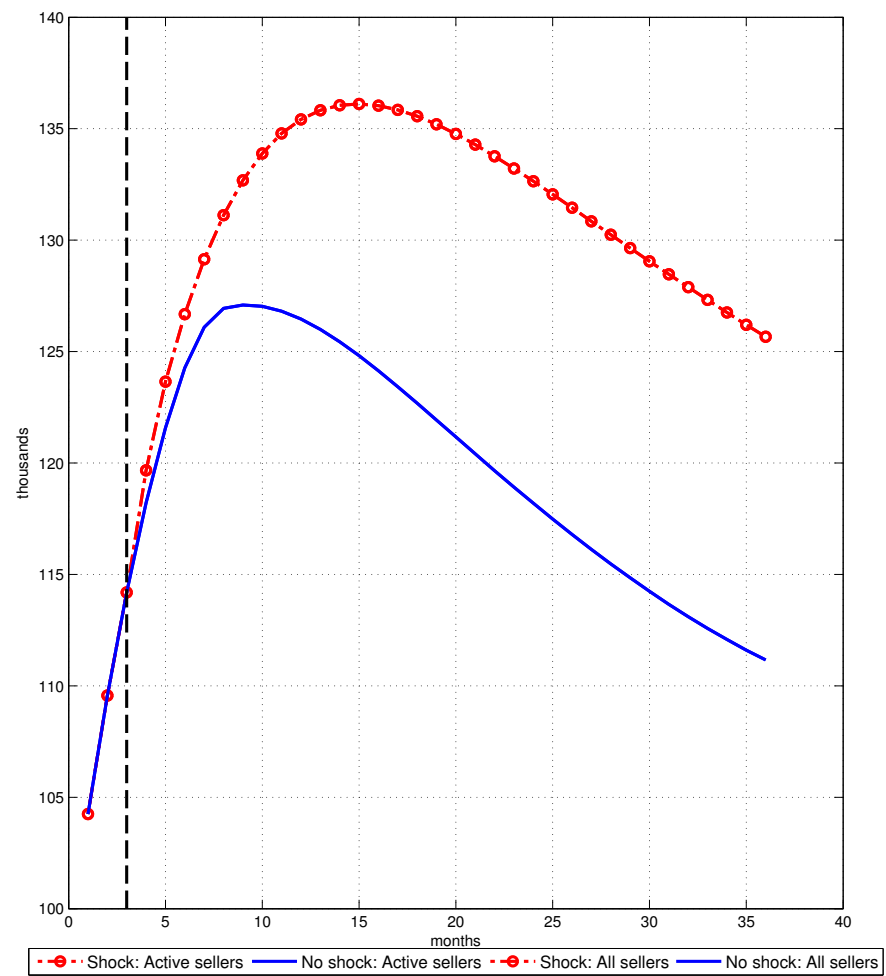

(b) Number of sellers

Second, consider how the second term in the expected prices (20) and (21) moves upon the shock. The increase in the option value to sell leads to an inflow of new sellers. Existing sellers keep trying to sell their houses - see Figure 8b. It shows the dynamics of the total number of sellers as well as the number of active sellers in the hot market of the auction model after the discount factor shock. In the hot market all sellers are active, because there are many buyers and the option value to sell is high. Thus, in the figure the total number of sellers and the number of active sellers are represented by one line. The solid blue line shows the dynamics of the number of sellers in the model with no shock, and the dashed red line with circles shows the number of sellers in the auction model after the shock. The number of sellers gradually increases in response to shock and slowly reverts back, because the shock is persistent but temporary.

In the hot market, when there are so many buyers that they are crowded out of the market, the number of active buyers is the one that makes the marginal buyer indifferent between searching and not searching. A rise in the option value to buy will create an incentive for marginal buyers to enter the market. Figure 8 a illustrates this shift. It plots the dynamics of the total number of buyers as well as the number of active buyers in the auction model after the shock. The black solid line shows the total number of buyers in the hot market in the model with no shock. The red dashed line shows the number of active buyers in the hot market in the model with no shock. Since the model starts in the hot market, the number of active buyers is less than the total number of buyers, but as the model converges to the steady-state and leaves the hot market, the number of active buyers increases till it equals the total number of buyers. The blue line 
with crosses and red dashed line with circles shows the total number of buyers and the number of active buyers in the mode with shock. When the shock hits, the marginal buyers switch from not searching to searching, increasing $B_{t}^{a}$.

Figure 9: The dynamics of the premium $\frac{\varphi\left(\theta_{t}\left(1-F\left(\bar{x}_{t}\right)\right)\right.}{\pi\left(\bar{x}_{t}, \theta_{t}\right)}$ in the auction model

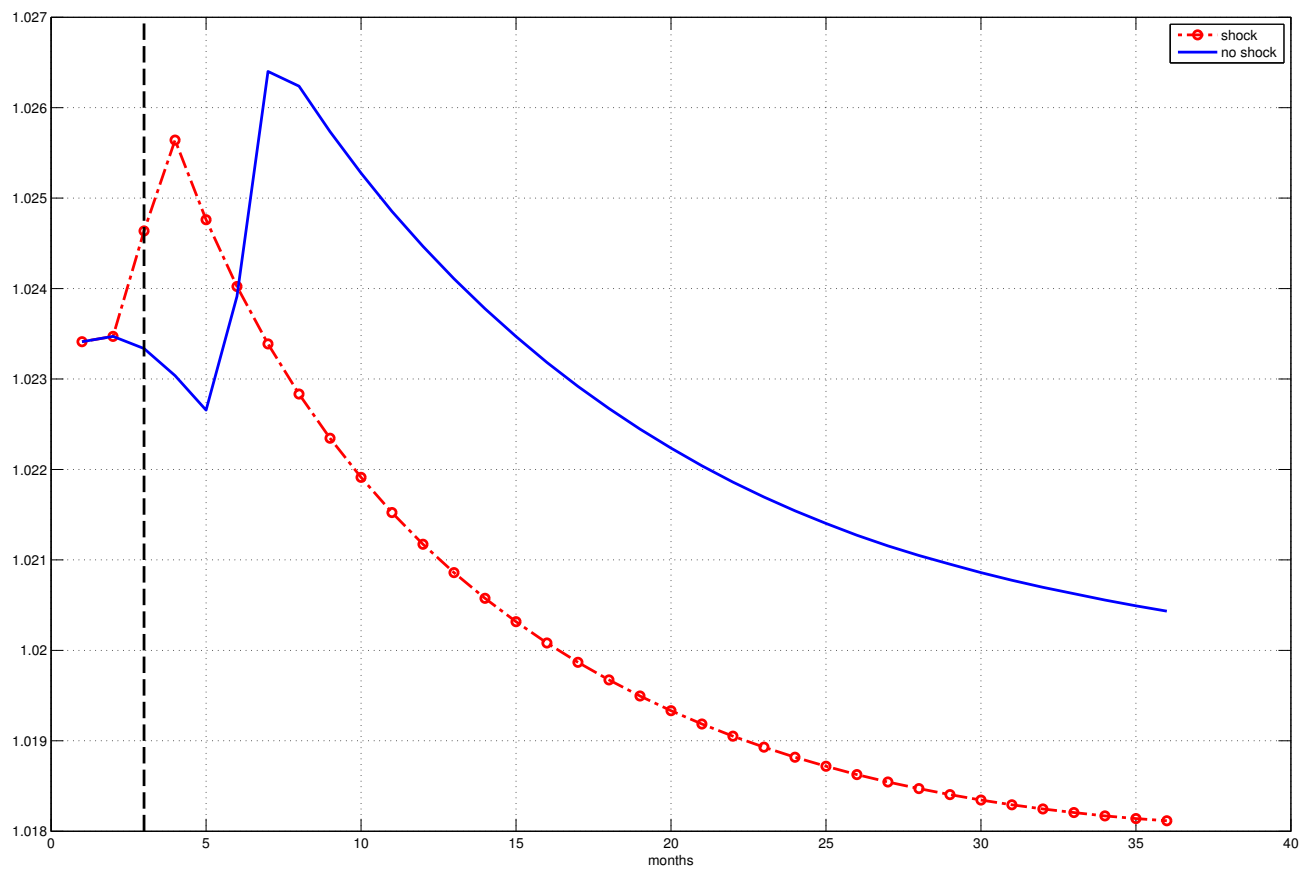

Because the number of sellers reacts slowly $S_{t}=S_{t}^{a}$ and the number of active buyers $B_{t}^{a}$ increases momentarily, the tightness of the housing market $\theta_{t}=B_{t}^{a} / S_{t}^{a}$ increases. In the auction model, the increase in tightness increases the argument $z_{t}=\theta_{t}\left(1-F\left(\bar{x}_{t}\right)\right)$ in the premium $\frac{\varphi\left(\theta_{t}\left(1-F\left(\bar{x}_{t}\right)\right)\right.}{\pi\left(\bar{x}_{t}, \theta_{t}\right)}=\frac{\varphi(z)}{1-\exp (-z)}$ (see Figure 9, where the function $\varphi(z) /(1-\exp (-z))$ is increasing in $z$. The increase in the discount factor will slightly increase the threshold match-specific value $\bar{x}$, but the effect of the tightness dominates and increases the premium. So in the auction model the shock leads to buyers who were out the market to start searching, which tightens the market, increasing the premium in (20). In contrast, in the Nash bargaining model the share $\alpha$ in (21) is fixed and does not change. Hence, when the present value of the match-specific housing services $P V_{x}$ increases, prices in the auction model react more.

\section{Momentum}

Predictions of both models are consistent with findings in the literature on the positive autocorrelation in the growth rates of house prices up to one year, or in other words, momentum (see, for example, Guren (2014), Glaeser, Gyourko, Morales, and Nathanson (2014), Case and Shiller (1989), Head, Lloyd-Ellis, and Sun (2014), Cho (1996), Capozza, Hendershott, and Mack (2004), Abraham and Hendershott (1994)). Figure 10 shows the quarterly autocorrelation of the prices after the discount factor shock with the critical level $+-2 / \sqrt{T}$ for 95 percent significance as the line where $T=9$ is the length of the simulated series. The first autocorrelation is 
significant in both models, but is lower if the price is determined in an auction. The quantitative predictions are in line with empirical evidence on the autocorrelations of the average auctionbased prices and average bargained prices in Genesove and Hansen (2014). That paper analyzes the home prices in Australia's two largest cities, where auctions are widely used as the price determination mechanism. It documents that the bargained and auction price growth exhibits positive first-order autocorrelation. Autocorrelation of the auction-based prices is lower (close to zero in Sydney and positive in Melbourne) than of the bargained prices. This finding is consistent with theoretical predictions in Figure 10.

Figure 10: The quarterly autocorrelations functions in the auction and Nash bargaining models

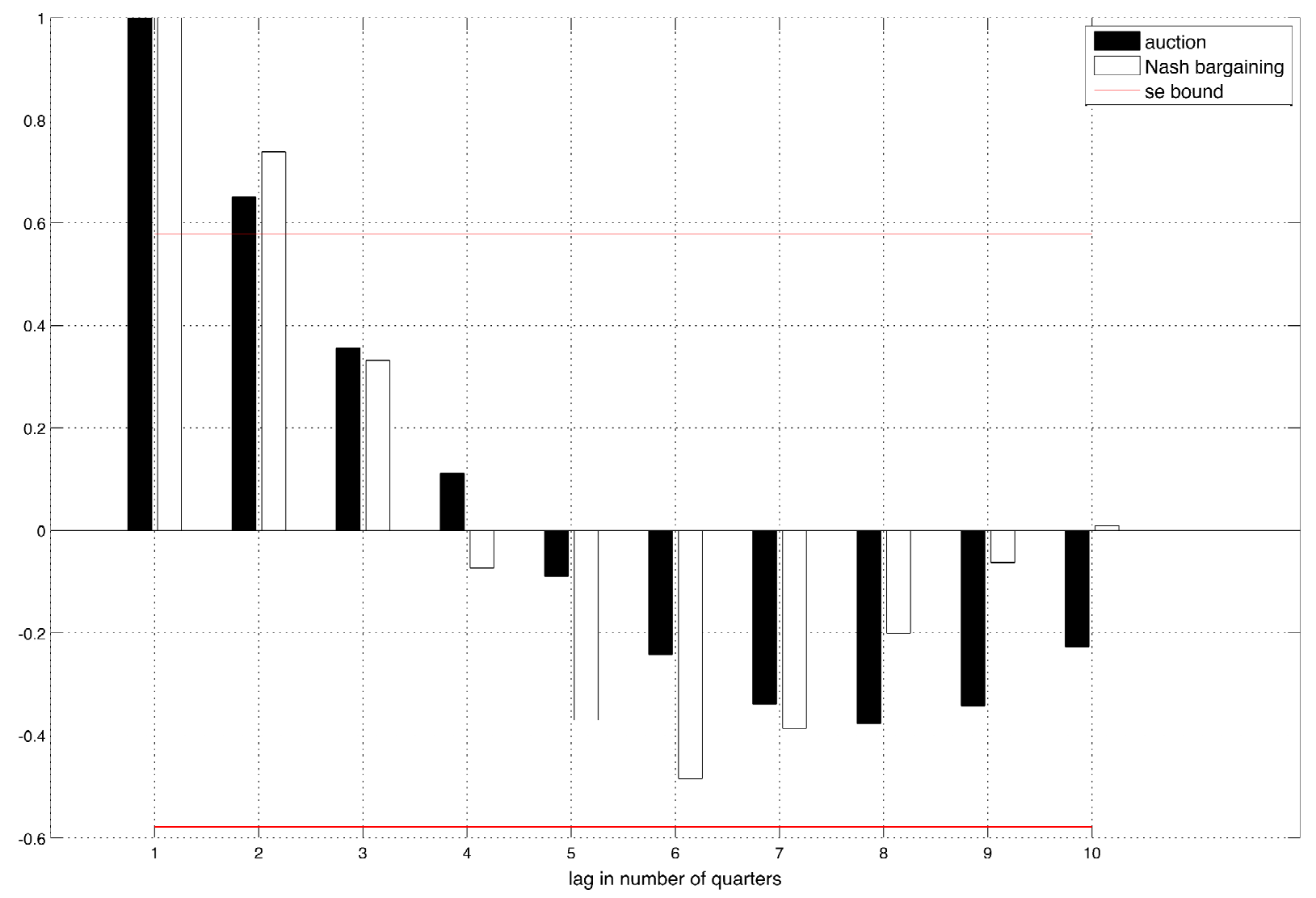

\section{Constrainted Pareto efficient allocation}

This section explores whether the equilibrium allocations produced by the auction and Nash bargaining search models are constrained Pareto efficient.

The constrained Pareto efficient allocation is a solution of a social planner problem, constrained by the search frictions. In particular, given the current state of the economy $\left(B_{t}, S_{t}, z_{t}\right)$, the social planner will decide how many new sellers $H_{t}$ will enter the market, how many buyers $B_{t}^{a}$ and sellers $S_{t}^{a}$ are active out of the pool of all buyers and sellers. Then every active buyer will 
be sent to an active seller according to the same Poisson process as in the decentralized auction and Nash bargaining models. Given the meeting between an active buyers and active sellers, buyers draw a realization of a match-specific value of housing services $x$. After observing these realizations the social planner must decide whether to distribute a house from an active seller today of wait till tomorrow, and, if the house is distributed, which buyer gets the house.

Since the values for a house are independently and identically distributed over time and over buyers, if the social planner allocates the house, the efficient allocation involves distributing the house to the buyer with the highest valuation. Therefore, to decide whether to distribute the house at all in the current period, the social planner compares the social benefits from distributing the house to the buyer with the highest valuation today and leaving the house on the market till tomorrow. The solution can be characterized by the threshold value of housing services $\bar{x}_{t}$, such that if the highest draw $x$ of the housing services exceeds $\bar{x}_{t}$, the house is distributed and vice versa. The threshold $\bar{x}_{t}$ is determined endogenously, and can vary over time.

The social planner chooses a sequence $\left\{H_{t}, S_{t}^{a}, B_{t}^{a}, \bar{x}_{t}\right\}_{t=0}^{\infty}$ in order to maximize the present discounted flow of housing services from all the houses, given the initial number of buyers $B_{0}>0$ and sellers $S_{0}>0$ and the aggregate state for the shock $z_{0}>0$,

$$
\begin{aligned}
\max _{\left\{\bar{x}_{t}, S_{t}^{a}, B_{t}^{a}, H_{t}\right\}_{t=0}^{\infty}} & \sum_{t=0}^{\infty} \\
& -\beta^{t}\left[S_{t}^{a} \pi\left(\bar{x}_{t}, \theta_{t}\right) \frac{\beta E\left[x_{(1) t} \mid x_{(1) t} \geq \bar{x}_{t}\right]}{1-\beta}-w B_{t}\right. \\
B_{t+1} & \left.=c_{t}^{a}-c^{b} B_{t}^{a}-T C\left(H_{t}\right)\right] \\
S_{t+1} & =S_{t}+H_{t}-\pi\left(\bar{x}_{t}, \theta_{t}\right) S_{t}^{a} \\
z_{t+1} & =\rho z_{t}+\varepsilon_{t} \\
0 & \leq S_{t}^{a} \leq S_{t} \\
0 & \leq B_{t}^{a} \leq B_{t} \\
B_{0} & >0, S_{0}>0, z_{0}>0 \text { given }
\end{aligned}
$$

where the total costs of construction are quadratic $T C\left(H_{t}\right)=c^{h} H_{t}+\frac{\psi}{2} H_{t}^{2}$ as before, $\pi\left(\bar{x}_{t}, \theta_{t}\right)$ is a probability of distributing a house and $E\left[x_{(1) t} \mid x_{(1) t} \geq \bar{x}_{t}\right]$ is an expectation of the highest value of housing services, conditional on the highest value exceeding the threshold $\bar{x}_{t}$ for distributing the house. The expectation in $E\left[x_{(1) t} \mid x_{(1) t} \geq \bar{x}_{t}\right]$ is taken both over the number of active buyers who visit a seller and over the realized values of those buyers.

Lemma 3 in Appendix A.2 shows that the probability of distributing a house is $\pi\left(\bar{x}_{t}, \theta_{t}\right)=$ $1-\exp \left(-\theta_{t}\left(1-F\left(\bar{x}_{t}\right)\right)\right)$, which, intuitively, is one minus the probability that no one out of $\theta_{t}$ buyers will have valuation higher than the threshold value. The conditional expectation of the maximum valuations is $E\left[x_{(1) t} \mid x_{(1) t} \geq \bar{x}_{t}\right]=\bar{x}_{t}+\frac{\varphi\left(\theta_{t}\left(1-F\left(\bar{x}_{t}\right)\right)\right.}{\lambda \pi\left(\bar{x}_{t}, \theta_{t}\right)}=\bar{x}_{t}+\frac{\int_{\bar{x}_{t}}^{\infty} \pi\left(x, \theta_{t}\right) d x}{\pi\left(\bar{x}_{t}, \theta_{t}\right)}$ by the same lemma. The expected value has to at least be higher than the threshold $\bar{x}_{t}$ plus the expected surplus $\frac{\int_{\bar{x}_{t}}^{\infty} \pi\left(x, \theta_{t}\right) d x}{\pi\left(\bar{x}_{t}, \theta_{t}\right)}$, similarly to the per-period expected surplus of the seller in the auction model. The solution of the social planner problem is described in A.2.1.

The equilibrium allocation in the auction model is not socially optimal. For intuition for this result, consider the steady-state of the auction model and the social planner allocation. There are two main differences between the two: the choice of the tightness, $\theta$, and the choice of the 
threshold value for selling (distributing) the house $\bar{x}$. In the steady state of the auction model the tightness and the threshold value can be found from

$$
\begin{aligned}
\varphi(\theta(1-F(\bar{x}))) & =\frac{\lambda(1-\beta)\left(c^{s}+\frac{(1-\beta)}{\beta} M C(d)\right)}{\beta} \\
\bar{x} & =\frac{1}{\lambda}+\frac{\beta \pi}{\lambda(1-\beta) \theta}+\frac{(1-\beta)}{\beta} M C(d)-c^{b}-w
\end{aligned}
$$

and in the steady state of the solution of the social planner problem -

$$
\begin{aligned}
\varphi(\theta(1-F(\bar{x})))-\pi(\bar{x}, \theta) & =\frac{\lambda(1-\beta)\left(c^{s}+\frac{(1-\beta)}{\beta} M C(d)\right)}{\beta} \\
\bar{x} & =\frac{\beta \pi}{\lambda(1-\beta) \theta}+\frac{(1-\beta)}{\beta} M C(d)-c^{b}-w .
\end{aligned}
$$

In the social planner problem the equation for the tightness has an extra $-\pi(\bar{x}, \theta)$ term. This term represents the market thinness externality that leads to suboptimal the tightness in the auction model. In the auction model, when the seller makes decisions, she ignores how these decisions change the composition of the buyers and sellers in the economy, and hence the meeting probabilities. For example, if the seller sells the house, the number of sellers, available for meeting with buyers, will decrease making the market thinner. The seller ignores this externality in the equilibrium, whereas in the constrained Pareto efficient allocation it is internalized.

The expression for the threshold value in the auction model has additional $1 / \lambda$ term, making the threshold value in the auction model higher as compared to the socially efficient allocation. This comparison is not immediate, because the equations include other endogenously determined variables, and is proved in Appendix A.2.2. Higher threshold value $\bar{x}$ in the auction model is a consequence of the static inefficiency of the optimal auction. The seller in the auction model behaves as a monopolist, which leads to higher prices, and hence higher threshold value $\bar{x}$ for distributing the house. This static inefficiency in the auction model will have dynamic consequences. Because the seller has higher threshold value $\bar{x}$, she will keep the house on the market longer as compared to what the social planner would choose. In other words, the seller will suboptimally choose to exercise this option value to sell too late. Board (2007) finds a similar prediction, although in a different setup.

The market thinness externality and the dynamic distortion are the two reasons the auction model does not produce the socially efficient allocation. The comparison of the equilibrium allocation in the Nash bargaining model and the socially optimal allocation is more involved and depends on the parameter values. However, in general in the random search models with Nash bargaining the equilibrium allocation does not coincide with the socially optimal allocation, unless the bargaining power is chosen "just right" 12 .

\footnotetext{
${ }^{12}$ The Hosios (1990) condition is to set the bargaining power equal to the elasticity of the meeting probability with respect to tightness to produce the equilibrium allocation in the standard labor search model that is socially optimal. However, the model in this paper differs from the standard labor search model, because there is no turnover of houses. And mechanical setting of the bargaining power to the elasticity of the meeting probability with respect to the tightness will not make the equilibrium allocation, with in the Nash bargaining price-setting mechanism, socially efficient.
} 
The gap between the equilibrium search models and the socially efficient allocation calls for study of the optimal government policy, and is the next step in this research agenda.

\section{Conclusion}

Auctions are widely employed in housing markets. In some cases, notably in Australia, UK, New Zealand ${ }^{13}$ and in US for foreclosed properties, the auctions take standardized forms. In others, sellers confronted with multiple interested buyers run informal auctions, inviting bids and rebids until a single buyer remains. This paper studies the role of auctions in housing markets, comparing a model with auctions to the standard model, where only one-on-one bargaining determines prices.

In hot markets, where each seller attracts multiple buyers, an auction is highly effective at selecting the buyer with the highest valuation. Optimal selection makes the market more efficient and results in higher prices and higher welfare. If sellers pick one of many interested buyers at random and negotiate only with that buyer, the price-finding process is less efficient, because the randomly selected buyer is probably not the buyer who places the highest value on the house. In cold markets, it is common for only a single buyer to be interested in a house, so the seller picks a reservation price and the buyer decides whether to buy at that price or not.

There are alternative price-finding processes that arise in the housing market that are beyond the scope of this paper, but deserve further attention from researchers. First, other auction formats may be used to sell houses. If the buyer are risk neutral and their values are independently and identically distributed over time and over bidder, then, by the revenue equivalence, the expected revenue for the seller is the same. But studying housing auctions with affiliated and correlated over time housing valuations and risk-averse buyers could impact the implications of the search model. Second, in cold markets, where many houses are available to a buyer without competition from other buyers, the buyer effectively runs an auction by considering the prices of the suitable houses that are currently on the market and picking the lowest one. Third, another alternative-price finding process is alternating-offer bargaining. In setting where oneon-one bargaining occurs, it takes the alternating-offer form. Not only this process seen in the real world, its game-theoretic foundations are stronger than the Nash bargain and proved to change the implications of the job search model (Hall and Milgrom (2008)). Finally, auctions and bargaining can be combined. In the housing market, the seller first picks the buyer with the highest valuation and bargains with this buyer one-to-one. In used-car auctions, it is common for the winning bid to fall short of the seller's hidden reserve price. In that case, the winning bidder and the seller engage in bargaining to see if the seller will agree to a price below the earlier reserve or the buyer will agree to a price above his winning bid (Larsen $(2015))$.

This paper focuses on the price-finding and is stripped down in other respects. It makes no claim to do justice to all the complexities of the housing market. Rather, it points out that the model used for price-finding has important consequences for the volatility and responsiveness of the house prices to exogenous shocks. The amplification of the housing market shocks in the auction model as compared to the Nash bargain model comes from the differences in the outside

\footnotetext{
${ }^{13}$ see Lusht (1996) for Australia, Dotzour, Moorhead, and Winkler (1998) for New Zealand, Merlo and OrtaloMagné (2004) for UK
} 
options. In Nash bargaining, the outside option of the seller is to abandon negotiation and start the search process over again. In auction, the outside option of the seller is to sell the house to another interested buyer in the auction, which is especially important in a hot market.

\section{References}

Abraham, J. M. and P. H. Hendershott (1994, June). Bubbles in metropolitan housing markets. Working Paper 4774, National Bureau of Economic Research.

Albrecht, J., A. Anderson, E. Smith, and S. Vroman (2007). Opportunistic matching in the housing market. International Economic Review 48(2), 641-664.

Albrecht, J., P. A. Gautier, and S. Vroman (2015). Directed search in the housing market. Review of Economic Dynamics, -.

Anenberg, E. and P. Bayer (2013, April). Endogenous sources of volatility in housing markets: The joint buyer-seller problem. (18980).

Badderley, A., I. Barany, R. Schneider, and W. Weil (2007). Spatial point processes and their applications. In W. Weil (Ed.), Stochastic Geometry, Volume 1892 of Lecture Notes in Mathematics, pp. 1-75. Springer Berlin Heidelberg.

Board, S. (2007). Selling options. Journal of Economic Theory 136(1), 324 - 340.

Bulow, J. and J. Roberts (1989). The simple economics of optimal auctions. Journal of Political Economy 97(5), pp. 1060-1090.

Burnside, C., M. Eichenbaum, and S. Rebelo (2013). Understanding booms and busts in housing market. Working Paper.

Caplin, A. and J. Leahy (2011). Trading frictions and house price dynamics. Journal of Money, Credit and Banking 43(7), pp. 283-303.

Capozza, D. R., P. H. Hendershott, and C. Mack (2004). An anatomy of price dynamics in illiquid markets: Analysis and evidence from local housing markets. Real Estate Economics 32(1), $1-32$.

Carrillo, P. E. (2012). An empirical stationary equilibrium search model of the housing market. International Economic Review 53(1), 203-234.

Case, K. E. and R. J. Shiller (1989). The efficiency of the market for single-family homes. The American Economic Review 79 (1), pp. 125-137.

Cho, M. (1996). Housing price dynamics: A survey of theoretical and empirical issues. Journal of Housing Research $\%$. 
Davis, M., A. Lehnert, and R. Martin (2008). The rent-price ratio for the aggregate stock of owner-occupied housing. Review of Income and Wealth 54(2), 279-284. data located at Land and Property Values in the U.S., Lincoln Institute of Land Policy http://www. lincolninst. edu/resources/.

Díaz, A. and B. Jerez (2013, August). House prices, sales, and time on the market: a searchtheoretic framework. International Economic Review 54(3), 837-872.

Dotzour, M., E. Moorhead, and D. Winkler (1998). The impact of auctions on residential sales prices in new zealand. Journal of Real Estate Research 16(1), 57-72.

Favilukis, J., S. C. Ludvigson, and S. V. Nieuwerburgh (2015). The macroeconomic effects of housing wealth, housing finance, and the limited risk-sharing in general equilibrium. Journal of Political Economy, forthcoming.

Genesove, D. and L. Han (2012). Search and matching in the housing market. Journal of Urban Economics 72(1), $31-45$.

Genesove, D. and J. Hansen (2014). Predicting dwelling prices with consideration of the sales mechanism. Reserve Bank of Australia Research Discussion Paper.

Glaeser, E. L. and J. Gyourko (2003). The impact of building restrictions on housing affordability. FRBNY Economic Policy Review.

Glaeser, E. L., J. Gyourko, E. Morales, and C. G. Nathanson (2014). Housing dynamics: An urban approach. Journal of Urban Economics 81, 45 - 56.

Glaeser, E. L., J. Gyourko, and A. Saiz (2008). Housing supply and housing bubbles. Journal of Urban Economics 64(2), 198 - 217.

Green, R. K., S. Malpezzi, and S. K. Mayo (2005). Metropolitan-specific estimates of the price elasticity of supply of housing, and their sources. The American Economic Review 95(2), $334-339$.

Guren, A. (2014). The causes and consequences of house price momentum. Working Paper.

Guren, A. and T. McQuade (2013). How do foreclosurez exacerbate housing downturns? Working Paper.

Gyourko, J. and A. Saiz (2004). Reinvestment in the housing stock: the role of construction costs and the supply side. Journal of Urban Economics 55(2), 238 - 256.

Hall, R. E. and P. R. Milgrom (2008). The limited influence of unemployment on the wage bargain. American Economic Review 98(4), 1653-74.

Han, L. and W. C. Strange (2012). Bidding wars for houses. Working Paper.

Han, L. and W. C. Strange (2015). The microstructure of housing markets: Search, bargaining, and brokerage. Handbook of Regional and Urban Economics 5. 
Head, A., H. Lloyd-Ellis, and D. Stacey (2014). Neighborhoods, house prices and homeownership. Working Paper.

Head, A., H. Lloyd-Ellis, and H. Sun (2014). Search, liquidity, and the dynamics of house prices and construction. American Economic Review 104(4), 1172-1210.

Hedlund, A. (2015). The cyclical dynamics of illiquid housing, debt, and foreclosures. Quantitative Economics, forthcoming.

Hosios, A. J. (1990). On the efficiency of matching and related models of search and unemployment. The Review of Economic Studies 57(2), 279-298.

Krainer, J. (2001). A theory of liquidity in residential real estate markets. Journal of Urban Economics $49(1), 32-53$.

Landvoigt, T. (2014). Housing demand during the boom: The role of expectations and credit constraints. Working Paper.

Larsen, B. (2015). The efficiency of real-world bargaining: Evidence from wholesale used-auto auctions. Working Paper.

Lusht, K. M. (1996). A comparison of prices brought by english auctions and private negotiations. Real Estate Economics 24(4), 517-530.

Merlo, A. and F. Ortalo-Magné (2004). Bargaining over residential real estate: evidence from england. Journal of Urban Economics 56(2), 192 - 216.

Moen, E. R., P. T. Nenov, and F. Sniekers (2015). Buying first or selling first in housing markets. Working Paper.

Mortensen, D. T. and C. A. Pissarides (1994). Job creation and job destruction in the theory of unemployment. The Review of Economic Studies 61(3), 397-415.

Ngai, L. R. and K. D. Sheedy (2015). Moving house. Working Paper.

Ngai, L. R. and S. Tenreyro (2014). Hot and cold seasons in the housing market. American Economic Review 104(12), 3991-4026.

Novy-Marx, R. (2009). Hot and cold markets. Real Estate Economics 37(1), 1 - 22.

Piazzesi, M. and M. Schneider (2009). Momentum traders in the housing market: survey evidence and a search model. American Economic Review Papers and Proceedings 99(2), 406-411.

Piazzesi, M. and M. Schneider (2012). Inflation and the price of real assets. Working Paper.

Piazzesi, M., M. Schneider, and J. Stroebel (May 2014). Segmented housing search. Working Paper.

Quan, D. C. (2002). Market mechanism choice and real estate disposition: Search versus auction. Real Estate Economics 30(3), 365-384. 
Wheaton, W. C. (1990). Vacancy, search, and prices in a housing market matching model. Journal of Political Economy 98(6), pp. 1270-1292.

\section{A Theoretical appendix}

\section{A.1 Proof of propositions}

\section{Proof of proposition 2}

We want to prove that the interim value functions of a buyer and seller satisfy

$$
\begin{aligned}
W_{t}^{S}\left(\bar{p}_{t}, N\right) & =\beta\left(G\left(\bar{p}_{t}\right)^{N} V_{t+1}^{S}+\left(1-G\left(\bar{p}_{t}\right)^{N}\right) \bar{p}_{t}+\int_{\bar{p}_{t}}^{\infty} M(y, N) d y\right) \\
V_{t}^{B}(x, N) & =\beta\left(V_{t+1}^{B}+\int_{\bar{p}_{t}}^{\max \left\{\bar{p}_{t}, b_{t}(x)\right\}} G(y)^{N-1} d y\right)
\end{aligned}
$$

\section{A.1.1 Seller}

Consider the seller first. The seller's value function from (7) is

$$
W_{t}^{S}\left(\bar{p}_{t}, N\right)= \begin{cases}\beta\left(G\left(\bar{p}_{t}\right)^{N} V_{t+1}^{S}+N G\left(\bar{p}_{t}\right)^{N-1}\left(1-G\left(\bar{p}_{t}\right)\right) \bar{p}_{t}+\int_{\bar{p}_{t}}^{\infty} y m(y, N) d y\right) & \text { if } N \geq 1 \\ \beta V_{t+1}^{S} & \text { if } N=0\end{cases}
$$

the cumulative distribution function of the second order statistic is $M(y, N)=1-N G(y)^{N-1}(1-$ $G(y))-G(y)^{N}$ if $y \geq \bar{p}_{t}$ and zero otherwise, and $m(y, N)=-\partial M(y, N) / \partial y$.

Applying the integration by parts to the last term in case $N \geq 0$, we get

$$
\begin{array}{r}
\int_{\bar{p}_{t}}^{\infty} y m(y, N) d y=-\int_{\bar{p}_{t}}^{\infty} y d M(y, N)=-\left.y M(y, N)\right|_{\bar{p}_{t}} ^{\infty}-\int_{\bar{p}_{t}}^{\infty} M(y, N) d y= \\
=\bar{p}_{t} M\left(\bar{p}_{t}, N\right)+\int_{\bar{p}_{t}}^{\infty} M(y, N) d y
\end{array}
$$

The interim value function of the seller in case $N \geq 0$ is then

$$
\begin{array}{r}
\beta\left(G\left(\bar{p}_{t}\right)^{N} V_{t+1}^{S}+N G\left(\bar{p}_{t}\right)^{N-1}\left(1-G\left(\bar{p}_{t}\right)\right) \bar{p}_{t}+\bar{p}_{t} M\left(\bar{p}_{t}, N\right)+\int_{\bar{p}_{t}}^{\infty} M(y, N) d y\right)= \\
=\beta\left(G\left(\bar{p}_{t}\right)^{N} V_{t+1}^{S}+N G\left(\bar{p}_{t}\right)^{N-1}\left(1-G\left(\bar{p}_{t}\right)\right) \bar{p}_{t}+\right. \\
\left.+\bar{p}_{t}\left(1-N G\left(\bar{p}_{t}\right)^{N-1}\left(1-G\left(\bar{p}_{t}\right)\right)-G\left(\bar{p}_{t}\right)^{N}\right)+\int_{\bar{p}_{t}}^{\infty} M(y, N) d y\right)= \\
=\beta\left(G\left(\bar{p}_{t}\right)^{N} V_{t+1}^{S}+\bar{p}_{t}\left(1-G\left(\bar{p}_{t}\right)^{N}\right)+\int_{\bar{p}_{t}}^{\infty} M(y, N) d y\right)
\end{array}
$$

Hence, the value function of the seller is

$$
W_{t}^{S}\left(\bar{p}_{t}, N\right)=\beta\left(G\left(\bar{p}_{t}\right)^{N} V_{t+1}^{S}+\bar{p}_{t}\left(1-G\left(\bar{p}_{t}\right)^{N}\right)+\int_{\bar{p}_{t}}^{\infty} M(y, N) d y\right)
$$


which includes both $N=0$ and $N \geq 1$.

We want to show

$$
V_{t}^{S}=\beta V_{t+1}^{S}+\max \left\{\frac{\beta \varphi\left(\theta_{t} e^{-\lambda \bar{x}_{t}}\right)}{\lambda(1-\beta)}-c^{s}, 0\right\}
$$

Consider the seller's value function and interim value function

$$
\begin{aligned}
V_{t}^{S}\left(\bar{p}_{t}, N\right) & =\beta\left(G\left(\bar{p}_{t}\right)^{N} V_{t+1}^{S}+\left(1-G\left(\bar{p}_{t}\right)^{N}\right) \bar{p}_{t}+\int_{\bar{p}_{t}}^{\infty} M(y, N) d y\right) \\
V_{t}^{S} & =\max \left\{\max _{\bar{p}} E_{N} W_{t}^{S}(\bar{p}, N)-c^{s}, \beta V_{t+1}^{S}\right\}
\end{aligned}
$$

We can take the expectation of the interim value function over the number of buyers $N \sim$ $\operatorname{Poisson}(\theta)$, which involves calculating

$$
E G\left(\bar{p}_{t}\right)^{N}=\sum_{n=0}^{\infty} \frac{e^{-\theta} \theta^{n}}{n !} G\left(\bar{p}_{t}\right)^{n}=\sum_{n=0}^{\infty} \frac{e^{-\theta}\left(\theta G\left(\bar{p}_{t}\right)\right)^{n}}{n !}=e^{-\theta} e^{\theta G\left(\bar{p}_{t}\right)}=e^{-\theta\left(1-G\left(\bar{p}_{t}\right)\right)}
$$

and $E \int_{\bar{p}_{t}}^{\infty} M(y, N) d y=\int_{\bar{p}_{t}}^{\infty} E M(y, N) d y$, which follows from Fubini theorem, and now

$$
\begin{array}{r}
E M(y, N)=E\left(1-N G(y)^{N-1}(1-G(y))-G(y)^{N}\right)=1-e^{-\theta(1-G(y))}- \\
-(1-G(y)) E\left(N G(y)^{N-1}\right)=1-e^{-\theta(1-G(y))}-(1-G(y)) e^{-\theta} \sum_{n=0}^{\infty} \frac{n \theta^{n} G(y)^{n-1}}{n !}= \\
=1-e^{-\theta(1-G(y))}-(1-G(y)) e^{-\theta} \theta \sum_{n=1}^{\infty} \frac{\theta^{n-1} G(y)^{n-1}}{(n-1) !}=1-e^{-\theta(1-G(y))}- \\
-(1-G(y)) e^{-\theta} \theta e^{\theta G(y)}=1-e^{-\theta(1-G(y))}-(1-G(y)) \theta e^{-\theta(1-G(y))}
\end{array}
$$

The expectation of the seller's interim value function over the number of buyers $N$ becomes

$$
\beta\left(e^{-\theta\left(1-G\left(\bar{p}_{t}\right)\right)} V_{t+1}^{S}+\left(1-e^{-\theta\left(1-G\left(\bar{p}_{t}\right)\right)}\right) \bar{p}_{t}+\int_{\bar{p}_{t}}^{\infty}\left[1-e^{-\theta(1-G(y))}-(1-G(y)) \theta e^{-\theta(1-G(y))}\right] d y\right)
$$

where the distribution of the equilibrium bid is

$$
\begin{aligned}
G(y) & =P(b(x) \leq y)=P\left(\frac{x}{1-\beta}-V_{t+1}^{B} \leq y\right)=P\left(x \leq(1-\beta)\left(V_{t+1}^{B}+y\right)\right)= \\
& =F\left((1-\beta)\left(V_{t+1}^{B}+y\right)\right) \\
G^{\prime}(y) & =(1-\beta) F^{\prime}\left((1-\beta)\left(V_{t+1}^{B}+y\right)\right)=\lambda(1-\beta) e^{-\lambda(1-\beta)\left(V_{t+1}^{B}+y\right)}= \\
& =\lambda(1-\beta)\left(1-F\left((1-\beta)\left(V_{t+1}^{B}+y\right)\right)\right)=\lambda(1-\beta)(1-G(y))
\end{aligned}
$$

and the second term of the last integral from 49 is

$$
\begin{aligned}
& \int_{\bar{p}_{t}}^{\infty}(1-G(y)) \theta e^{-\theta(1-G(y))} d y=\theta \int_{\bar{p}_{t}}^{\infty}(1-G(y)) e^{-\theta(1-G(y))} \frac{G^{\prime}(y)}{\lambda(1-\beta)(1-G(y))} d y= \\
= & \frac{1}{\lambda(1-\beta)} \int_{\bar{p}_{t}}^{\infty} e^{-\theta(1-G(y))} d(\theta(G(y)-1))=\left.\frac{1}{\lambda(1-\beta)} e^{\theta(G(y)-1)}\right|_{\bar{p}} ^{\infty}=\frac{1}{\lambda(1-\beta)}\left(1-e^{\theta(G(\bar{p})-1)}\right)
\end{aligned}
$$


while the first term in the last integral from 49 is

$$
\begin{array}{r}
\int_{\bar{p}_{t}}^{\infty}\left[1-e^{-\theta(1-G(y))}\right] d y=\int_{\bar{p}_{t}}^{\infty}\left[1-e^{-\theta(1-G(y))}\right] \frac{G^{\prime}(y)}{\lambda(1-\beta)(1-G(y))} d y= \\
=-\int_{\bar{p}_{t}}^{\infty} \frac{1-e^{-\theta(1-G(y))}}{\lambda(1-\beta) \theta(1-G(y))} d \theta(1-G(y))=-\frac{1}{\lambda(1-\beta)} \int_{\theta\left(1-G\left(\bar{p}_{t}\right)\right)}^{0} \frac{1-e^{-t}}{t} d t= \\
\left.=\frac{1}{\lambda(1-\beta)} \int_{0}^{\left.\theta\left(1-G\left(\bar{p}_{t}\right)\right)\right)} \frac{1-e^{-t}}{t} d t=\frac{1}{\lambda(1-\beta)} \varphi\left(\theta\left(1-G\left(\bar{p}_{t}\right)\right)\right)\right)
\end{array}
$$

where the function representing the last integral is denoted by $\varphi($.$) , that is$

$$
\varphi(z) \equiv \int_{0}^{z} \frac{1-e^{-t}}{t} d t
$$

The expectation of the seller's interim value function over the number of buyers $N$ is simplified to

$$
\beta\left(e^{-\theta\left(1-G\left(\bar{p}_{t}\right)\right)} V_{t+1}^{S}+\left(1-e^{-\theta\left(1-G\left(\bar{p}_{t}\right)\right)}\right)\left(\bar{p}_{t}-\frac{1}{\lambda(1-\beta)}\right)+\frac{1}{\lambda(1-\beta)} \varphi\left(\theta\left(1-G\left(\bar{p}_{t}\right)\right)\right)\right)
$$

The optimal reservation price is determined from the first order condition with respect to the reservation price $\bar{p}_{t}$ :

$$
\begin{aligned}
& e^{-\theta\left(1-G\left(\bar{p}_{t}\right)\right)} \theta G^{\prime}\left(\bar{p}_{t}\right) V_{t+1}^{S}-\theta G^{\prime}\left(\bar{p}_{t}\right) e^{-\theta\left(1-G\left(\bar{p}_{t}\right)\right)}\left(\bar{p}_{t}-\frac{1}{\lambda(1-\beta)}\right)+\left(1-e^{-\theta\left(1-G\left(\bar{p}_{t}\right)\right)}\right)+ \\
& +\frac{-\theta G^{\prime}(\bar{p}) \varphi^{\prime}\left(\theta\left(1-G\left(\bar{p}_{t}\right)\right)\right.}{\lambda(1-\beta)}=0 \\
& e^{-\theta\left(1-G\left(\bar{p}_{t}\right)\right)} \theta G^{\prime}\left(\bar{p}_{t}\right) V_{t+1}^{S}-\theta G^{\prime}\left(\bar{p}_{t}\right) e^{-\theta\left(1-G\left(\bar{p}_{t}\right)\right)}\left(\bar{p}_{t}-\frac{1}{\lambda(1-\beta)}\right)+\left(1-e^{-\theta\left(1-G\left(\bar{p}_{t}\right)\right)}\right)+ \\
& +\frac{-\theta G^{\prime}(\bar{p}) \frac{1-e^{-\theta\left(1-G\left(\bar{p}_{t}\right)\right)}}{\theta\left(1-G\left(\bar{p}_{t}\right)\right)}}{\lambda(1-\beta)}=0
\end{aligned}
$$

Hence,

$$
\bar{p}_{t}=V_{t+1}^{S}+\frac{1}{\lambda(1-\beta)}
$$

The expectation of the seller's interim value function over the number of buyers $N$ is simplifies further to

$$
\beta\left(V_{t+1}^{S}+\frac{1}{\lambda(1-\beta)} \varphi\left(\theta\left(1-G\left(\bar{p}_{t}\right)\right)\right)\right)
$$


To finish the proof, recall that the threshold match-specific value $\bar{x}_{t}$ is defined by $b_{t}\left(\bar{x}_{t}\right)=\bar{p}_{t}$. Hence, $G\left(b_{t}\left(\bar{x}_{t}\right)\right)=F\left(\bar{x}_{t}\right)=1-e^{-\lambda \bar{x}_{t}}$, and

$$
\beta\left(V_{t+1}^{S}+\frac{1}{\lambda(1-\beta)} \varphi\left(\theta e^{-\lambda \bar{x}_{t}}\right)\right)
$$

Combining the interim value function of the seller with the value function of the seller in the beginning of the period, we get the required result

$$
\begin{array}{r}
V_{t}^{S}=\max \left\{\max _{\bar{p}} E_{N} W_{t}^{S}(\bar{p}, N)-c_{s}, \beta V_{t+1}^{S}\right\}= \\
=\max \left\{\beta V_{t+1}^{S}+\frac{\beta}{\lambda(1-\beta)} \varphi\left(\theta e^{-\lambda \bar{x}_{t}}\right)-c_{s}, \beta V_{t+1}^{S}\right\}=\beta V_{t+1}^{S}+\max \left\{\frac{\beta \varphi\left(\theta e^{-\lambda \bar{x}_{t}}\right)}{\lambda(1-\beta)}-c_{s}, 0\right\}
\end{array}
$$

\section{A.1.2 Buyer}

Now consider the buyer. The value function of the buyer from (6) is

$$
W_{t}^{B}(x, N)= \begin{cases}\beta\left[\left(1-G\left(b_{t}\right)^{N-1}\right) V_{t+1}^{B}+\right. \\ +\left(G\left(b_{t}\right)^{N-1}-G\left(\bar{p}_{t}\right)^{N-1}\right) \int_{\bar{p}_{t}}^{b_{t}} \frac{\left(V_{t+1}^{H}(x)-y\right)}{\left(G\left(b_{t} t^{N-1}-G\left(\bar{p}_{t}\right)^{N-1}\right)\right.} d G(y)^{N-1} & \\ \left.+G\left(\bar{p}_{t}\right)^{N-1}\left(V_{t+1}^{H}(x)-\bar{p}_{t}\right)\right] & \text { if } b_{t} \geq \bar{p}_{t} \\ \beta V_{t+1}^{B} & \text { if } b_{t}<\bar{p}_{t}\end{cases}
$$

where $b_{t}(x)=V_{t+1}^{H}(x)-V_{t+1}^{B}$.

When $b_{t} \geq \bar{p}_{t}$, the value function simplifies to

$$
\begin{array}{r}
\beta\left[\left(1-G\left(b_{t}\right)^{N-1}\right) V_{t+1}^{B}+\int_{\bar{p}_{t}}^{b_{t}}\left(V_{t+1}^{H}(x)-y\right) d G(y)^{N-1}+G\left(\bar{p}_{t}\right)^{N-1}\left(V_{t+1}^{H}(x)-\bar{p}_{t}\right)\right]= \\
\beta\left[\left(1-G\left(b_{t}\right)^{N-1}\right) V_{t+1}^{B}+\int_{\bar{p}_{t}}^{b_{t}}\left(b_{t}+V_{t+1}^{B}-y\right) d G(y)^{N-1}+G\left(\bar{p}_{t}\right)^{N-1}\left(b_{t}+V_{t+1}^{B}-\bar{p}_{t}\right)\right]= \\
=\beta\left[\left(1-G\left(b_{t}\right)^{N-1}\right) V_{t+1}^{B}+\left(b_{t}+V_{t+1}^{B}\right)\left(G\left(b_{t}\right)^{N-1}-G\left(\bar{p}_{t}\right)^{N-1}\right)-\int_{\bar{p}_{t}}^{b_{t}} y d G(y)^{N-1}\right. \\
\left.+G\left(\bar{p}_{t}\right)^{N-1}\left(b_{t}+V_{t+1}^{B}-\bar{p}_{t}\right)\right]=\beta\left(V_{t+1}^{B}+b_{t} G\left(b_{t}\right)^{N-1}-\bar{p}_{t} G\left(\bar{p}_{t}\right)^{N-1}-\int_{\bar{p}_{t}}^{b_{t}} y d G(y)^{N-1}\right)= \\
=\beta\left(V_{t+1}^{B}+b_{t} G\left(b_{t}\right)^{N-1}-\bar{p}_{t} G\left(\bar{p}_{t}\right)^{N-1}-\left(\left.y G(y)^{N-1}\right|_{\bar{p}_{t}} ^{b_{t}}+\int_{\bar{p}_{t}}^{b_{t}} G(y)^{N-1} d y\right)\right)
\end{array}
$$

Finally, we have

$$
W_{t+1}^{B}(x, N)=\beta\left(V_{t+1}^{B}+\int_{\bar{p}_{t}}^{\max \left\{\bar{p}_{t}, b_{t}\right\}} G(y)^{N-1} d y\right)
$$

We want to show

$$
V_{t}^{B}=\beta V_{t+1}^{B}+\max \left\{\frac{\beta \pi\left(\bar{x}_{t}, \theta_{t}\right)}{\lambda(1-\beta) \theta_{t}}-c^{b}, 0\right\}-w
$$


The interim value function of the buyer is

$$
W_{t+1}^{B}(x, N)=\beta\left(V_{t+1}^{B}+\int_{\bar{p}_{t}}^{\max \left\{\bar{p}_{t}, b_{t}(x)\right\}} G(y)^{N-1} d y\right)
$$

Now we need to take the expectation both over the realization of the match-specific value $x$ and the total number of buyers $N$. Observe that $W_{t+1}^{B}(x, N)=\sum_{n=2}^{N}\left(W_{t+1}^{B}(x, n)-W_{t+1}^{B}(x, n-\right.$ $1))+W_{t+1}^{B}(x, 1)$ and

$$
\begin{aligned}
W_{t+1}^{B}(x, 1) & =\beta\left(V_{t+1}^{B}+\max \left\{b_{t}(x)-\bar{p}_{t}, 0\right\}\right)=\beta \max \left\{V_{t+1}^{B}, \frac{x-\bar{x}}{1-\beta}\right\} \\
W_{t+1}^{B}(x, n)-W_{t+1}^{B}(x, n-1) & =\beta\left(\int_{\bar{p}_{t}}^{\max \left\{\bar{p}_{t}, b_{t}(x)\right\}}\left(G(y)^{n-1}-G(y)^{n-2}\right) d y\right)= \\
& =\beta \int_{\bar{p}_{t}}^{\max \left\{\bar{p}_{t}, b_{t}(x)\right\}} G(y)^{n-2}(G(y)-1) \frac{G^{\prime}(y)}{\lambda(1-\beta)(1-G(y))} d y= \\
& =-\beta \int_{\bar{p}_{t}}^{\max \left\{\bar{p}_{t}, b_{t}(x)\right\}} G(y)^{n-2} d G(y)=-\left.\frac{\beta}{\lambda(1-\beta)} \frac{G(y)^{n-1}}{n-1}\right|_{\bar{p}_{t}} ^{\max \left\{\bar{p}_{t}, b_{t}(x)\right\}}= \\
& =\frac{\beta}{\lambda(1-\beta)} \min \left\{\frac{F\left(\bar{x}_{t}\right)^{n-1}-F(x)^{n-1}}{n-1}, 0\right\}
\end{aligned}
$$

Taking expectation over $x$ yields

$$
\begin{array}{r}
E_{x} W_{t+1}^{B}(x, 1)=\beta V_{t+1}^{B} F(\bar{x})+\beta \int_{\bar{x}}^{\infty}\left(\frac{x-\bar{x}}{1-\beta}\right) d F(x)=\beta V_{t+1}^{B} F(\bar{x})+ \\
\left.+\beta(1-F(\bar{x}))\left(\frac{1}{\lambda(1-\beta)}+\frac{\bar{x}}{1-\beta}-\bar{p}\right)\right)=\beta V_{t+1}^{B}+\beta \frac{(1-F(\bar{x}))}{\lambda(1-\beta)} \\
E_{x}\left[W_{t+1}^{B}(x, n)-W_{t+1}^{B}(x, n-1)\right]=\frac{\beta}{\lambda(1-\beta)} \int_{\bar{x}}^{\infty}\left(\frac{F\left(\bar{x}_{t}\right)^{n-1}-F(x)^{n-1}}{n-1}\right) d F(x)= \\
=\frac{\beta}{\lambda(1-\beta)(n-1)}\left[F(\bar{x})^{n-1}-F(\bar{x})^{n}-\left.\frac{F(x)^{n}}{n}\right|_{\bar{x}} ^{\infty}\right]= \\
=\frac{\beta}{\lambda(1-\beta)(n-1)}\left[F(\bar{x})^{n-1}-F(\bar{x})^{n}-\frac{1-F(\bar{x})^{n}}{n}\right]= \\
=\frac{\beta}{\lambda(1-\beta)(n-1)}\left[F(\bar{x})^{n-1}-F(\bar{x})^{n}-\frac{1}{n}+\frac{F(\bar{x})^{n}}{n}\right]= \\
=\frac{\beta}{\lambda(1-\beta)}\left[\frac{F(\bar{x})^{n-1}}{n-1}-\frac{1}{n(n-1)}-\frac{F(\bar{x})^{n}}{n}\right]
\end{array}
$$




$$
\begin{array}{r}
E_{x} W_{t+1}^{B}(x, N)=E_{x} W_{t+1}^{B}(x, 1)+\sum_{n=2}^{N} E_{x}\left[W_{t+1}^{B}(x, n)-W_{t+1}^{B}(x, n-1)\right]= \\
=\beta V_{t+1}^{B}+\beta \frac{(1-F(\bar{x}))}{\lambda(1-\beta)}+\frac{\beta}{\lambda(1-\beta)} \sum_{n=2}^{N}\left[\frac{F(\bar{x})^{n-1}}{n-1}-\frac{1}{n(n-1)}-\frac{F(\bar{x})^{n}}{n}\right]= \\
=\beta V_{t+1}^{B}+\beta \frac{(1-F(\bar{x}))}{\lambda(1-\beta)}+\frac{\beta}{\lambda(1-\beta)}\left(F(\bar{x})-\frac{F(\bar{x})^{N}}{N}-\sum_{n=2}^{N} \frac{1}{n(n-1)}\right)= \\
=\beta V_{t+1}^{B}+\beta \frac{1}{\lambda(1-\beta)}-\frac{\beta}{\lambda(1-\beta)}\left(\frac{F(\bar{x})^{N}}{N}+\sum_{n=2}^{N}\left(\frac{1}{(n-1)}-\frac{1}{n}\right)\right)= \\
=\beta V_{t+1}^{B}+\beta \frac{1}{\lambda(1-\beta)}-\frac{\beta}{\lambda(1-\beta)}\left(\frac{F(\bar{x})^{N}}{N}+1-\frac{1}{N}\right)= \\
=\beta V_{t+1}^{B}+\frac{\beta}{\lambda(1-\beta)} \frac{1-F(\bar{x})^{N}}{N}
\end{array}
$$

The expectation over the total number of other buyer: ${ }^{14}$ is

$$
\begin{aligned}
e^{-\theta} & \sum_{n=1}^{\infty} \frac{\theta^{n-1}}{(n-1) !} \frac{\left(1-F(\bar{x})^{n}\right)}{n}=\frac{e^{-\theta}}{\theta} \sum_{n=1}^{\infty} \frac{\theta^{n}}{n !}\left(1-F(\bar{x})^{n}\right)= \\
= & \frac{e^{-\theta}}{\theta}\left(e^{\theta}-1-e^{\theta F(\bar{x})}+1\right)=\frac{1-e^{-\theta(1-F(\bar{x}))}}{\theta}=\frac{\pi(\bar{x}, \theta)}{\theta}
\end{aligned}
$$

Thus,

$$
E_{N} E_{x} W_{t+1}^{B}(x, N)=\beta V_{t+1}^{B}+\frac{\beta}{\lambda(1-\beta)} \frac{\pi(\bar{x}, \theta)}{\theta}
$$

The value function of the buyer is then

$$
\begin{array}{r}
V_{t}^{B}=\max \left\{\beta V_{t+1}^{B}+\frac{\beta}{\lambda(1-\beta)} \frac{\pi(\bar{x}, \theta)}{\theta}-c^{b}, \beta V_{t+1}^{B}\right\}-w= \\
=\beta V_{t+1}^{B}+\max \left\{\frac{\beta}{\lambda(1-\beta)} \frac{\pi(\bar{x}, \theta)}{\theta}-c^{b}, 0\right\}-w
\end{array}
$$

Expected sales price We want to show that the expected price is

$$
\hat{p}=V_{t+1}^{S}+\frac{\beta \varphi\left(\theta_{t} e^{-\lambda \bar{x}_{t}}\right)}{\lambda(1-\beta) \pi\left(\bar{x}_{t}, \theta_{t}\right)}
$$

\footnotetext{
${ }^{14} n$ is the total number of buyers, $m=n-1$ is the number of other buyers $\sim$ Poisson $(\theta)$, hence the pdf for is $e^{-\theta} \frac{\theta^{m}}{m !} m=0,1, \ldots$ or $e^{-\theta} \frac{\theta^{n-1}}{(n-1) !} n=1,2$..
} 


$$
\begin{array}{r}
\hat{p}_{t}=E p_{t}=\frac{E_{N}\left[\bar{p}_{t} \operatorname{Pr}\left(\text { Sale at } \bar{p}_{t}\right)+E b_{(2) t} \operatorname{Pr}\left(\text { Sale at } b_{(2) t}\right)\right]}{E_{N} P(\text { Sale })}= \\
=\frac{E_{N}\left[\bar{p}_{t} N G\left(\bar{p}_{t}\right)^{N}\left(1-G\left(\bar{p}_{t}\right)\right)+\int_{\bar{p}_{t}}^{\infty} y d(-M(y, N))\right]}{E_{N}\left(1-G\left(\bar{p}_{t}\right)^{N}\right)}= \\
=\frac{E_{N}\left[\bar{p}_{t} N G\left(\bar{p}_{t}\right)^{N}\left(1-G\left(\bar{p}_{t}\right)\right)+\left(-\left.y M(y, N)\right|_{\bar{p}_{t}} ^{\infty}+\int_{\bar{p}_{t}}^{\infty} M(y, N) d y\right)\right]}{E_{N}\left(1-G\left(\bar{p}_{t}\right)^{N}\right)}= \\
=\frac{E_{N}\left[\bar{p}_{t} N G\left(\bar{p}_{t}\right)^{N}\left(1-G\left(\bar{p}_{t}\right)\right)+\bar{p}_{t} M\left(\bar{p}_{t}, N\right)+\int_{\bar{p}_{t}}^{\infty} M(y, N) d y\right]}{E_{N}\left(1-G\left(\bar{p}^{N}\right)\right.}= \\
=\frac{E_{N}\left[\bar{p}_{t}\left(1-G\left(\bar{p}_{t}\right)^{N}\right)+\int_{\bar{p}_{t}}^{\infty} M(y, N) d y\right]}{E_{N}\left(1-G\left(\bar{p}_{t}\right)^{N}\right)}=\bar{p}_{t}+\frac{E_{N} \int_{\bar{p}_{t}}^{\infty} M(y, N) d y}{E_{N}\left(1-G\left(\bar{p}_{t}\right)^{N}\right)}= \\
=V_{t+1}^{S}+\frac{1}{\lambda(1-\beta)}+\frac{\varphi\left(\theta_{t} e^{-\lambda \bar{x}_{t}}\right)-\pi\left(\bar{x}_{t}, \theta_{t}\right)}{\lambda(1-\beta) \pi\left(\bar{x}_{t}, \theta_{t}\right)}=V_{t+1}^{S}+\frac{\varphi\left(\theta_{t} e^{-\lambda \bar{x}_{t}}\right)}{\lambda(1-\beta) \pi\left(\bar{x}_{t}, \theta_{t}\right)}
\end{array}
$$

\section{Proof of proposition 4}

The solution for the steady-states in the auction and Nash bargaining models is summarized in Table 3. The inflow of new sellers and value functions are the same in both models, as can be seen from the table. To proof that the probability of sale in the auction model is less than in the Nash bargaining model and the expected house price $\hat{p}$ is higher in the auction model than in Nash bargaining model, we first proof the lemma 1 .

Table 3: The steady-state equilibrium in the auction and Nash bargaining models.

\begin{tabular}{|l|c|c|c|}
\hline \hline & Auction & & Nash bargaining \\
\hline \hline Inflow of new sellers $H$ & $d$ & $=$ & $d$ \\
\hline Seller v.f. $V^{S}$ & $\frac{\psi d+c^{h}}{\beta}$ & $=$ & $\frac{\psi d+c^{h}}{\beta}$ \\
\hline Prob of sale $\pi$ & $1-\exp (-z)$ & $<$ & $\frac{c^{s}+(1-\beta) V^{S}}{\beta\left(\frac{\alpha}{\lambda(1-\beta)}-V^{S}\right)}=\frac{\lambda(1-\beta)\left(c^{s}+(1-\beta) V^{S}\right)}{\beta\left(\alpha-\lambda(1-\beta) V^{S}\right)}$ \\
\hline Prices $\hat{p}$ & $V^{S}+\frac{\varphi(z)}{\lambda(1-\beta) \pi(z)}$ & $>$ & $V^{S}+\frac{\alpha}{\lambda(1-\beta)}$ \\
\hline Tightness $\theta$ & $z e^{\lambda \bar{x}}$ & & $\pi=(1-\exp (-\theta)) e^{-\lambda \bar{x}}$ \\
\hline Buyer v.f. $V^{B}$ & $\frac{1}{1-\beta}\left(\frac{\beta \pi}{\lambda(1-\beta) \theta}-c^{b}-w\right)$ & $>$ & $\frac{1}{1-\beta+\beta \pi / \theta}\left(\frac{\beta(1-\alpha) \pi}{\lambda(1-\beta) \theta}-c^{b}-w\right)$ \\
\hline Threshold $\bar{x}$ & $\bar{x}=\frac{1}{\lambda}+(1-\beta)\left(V^{S}+V^{B}\right)$ & $>$ & $\bar{x}=(1-\beta)\left(V^{S}+V^{B}\right)$ \\
\hline Number of sellers $S$ & $d / \pi$ & $>$ & $d / \pi$ \\
\hline Number of buyers $B$ & $S \theta$ & & $S \theta$ \\
\hline \hline
\end{tabular}

The shortcut "v.f" stands for value function. In the auction model the auxiliary variable $z=\theta e^{-\lambda \bar{x}}=$ $\frac{\lambda(1-\beta)\left(c^{s}+(1-\beta) V^{S}\right)}{\beta}$. In the Nash bargaining model the tightness $\theta$ and the threshold value $\bar{x}$ are found jointly as the solution of the two equations in the table.

Lemma 1. In the auction model $\varphi(z)>\pi(z) \forall z>0$ 
Proof. Let $z \equiv \theta e^{-\lambda \bar{x}}$ and $\varphi(z) \equiv \int_{0}^{z} \frac{1-e^{-y}}{y} d y$. We can now express the probability of sale $\pi(\bar{x}, \theta)=1-\exp \left(-\theta_{t} e^{-\lambda \bar{x}_{t}}\right)$ in auction as $\pi(\bar{x}, \theta)=\pi(z)=1-\exp (-z)$ and conclude that

$$
\begin{aligned}
\lim _{z \rightarrow 0} \frac{\varphi(z)}{\pi(z)} & =\lim _{z \rightarrow 0} \frac{(1-\exp (-z)) / z}{\exp (-z)}=\lim _{z \rightarrow 0} \frac{\exp (z)-1}{z}=\lim _{z \rightarrow 0} \frac{\exp (z)}{1}=1 \\
\varphi(0) & =\pi(0)=0 \\
(\varphi(z)-\pi(z))^{\prime} & =\frac{1-e^{-z}}{z}-e^{-z}=\frac{1-(1+z) e^{-z}}{z}>0
\end{aligned}
$$

Hence, $\varphi(z) / \pi(z)>1$.

Lemma 1 and $\alpha<1$ imply that the expected house price $\hat{p}$ is higher in the auction model than in the Nash bargaining model, and lemma 2 gives the result on the probability of sale.

Lemma 2. In steady state the probability of sale $\pi$ in the auction model is less than in the Nash bargaining model.

Proof. By lemma $1 \pi(z)=1-\exp (-z)<\varphi(z)$, hence in the auction model

$$
1-\exp (-z) \leq \varphi(z)=\frac{\lambda(1-\beta)\left(c^{s}+(1-\beta) V^{S}\right)}{\beta}
$$

The denominator of probability of sale in search has term $\alpha-\lambda(1-\beta) V^{S}$, which is less than one

$$
\begin{array}{r}
\alpha-\lambda(1-\beta) V^{S}<1 \\
\frac{\alpha}{\lambda(1-\beta)}-V^{S}<\frac{1}{\lambda(1-\beta)} \\
\frac{\alpha-1}{\lambda(1-\beta)}<V^{S}
\end{array}
$$

where the left-hand side is negative, because $\alpha \in(0,1)$ and the right-hand side is non-negative.

Since $\alpha-\lambda(1-\beta) V^{S}<1$, we have

$$
\pi_{A}=1-\exp (-z) \leq \varphi(z)=\frac{\lambda(1-\beta)\left(c^{s}+(1-\beta) V^{S}\right)}{\beta}<\frac{\lambda(1-\beta)\left(c^{s}+(1-\beta) V^{S}\right)}{\beta\left(\alpha-\lambda(1-\beta) V^{S}\right)}=\pi_{S}
$$

where $\pi_{A}, \pi_{S}$ is the probability of sale in the auction and Nash bargaining model, correspondingly.

The value function of the buyer is bigger in the auction model than in the Nash bargaining model, since $1-\beta<1-\beta+\beta \pi$ and $1>1-\alpha$. The threshold match-specific value $\bar{x}$ is higher in the auction model, since the value function of the seller is the same in both models, the value function of the buyer is bigger in the auction model and the auction model has additional positive term $E x=1 / \lambda$. The auction model in the steady-state has more sellers, because the probability of sale is lower than in the Nash bargaining model. The tightness can be higher or lower in the auction model as compared to the Nash bargaining model depending on the parameter values. 


\section{A.2 Results on the constrained Pareto efficient allocation}

Lemma 3. The probability of distributing a house in the social optimum is $\pi\left(\bar{x}_{t}, \theta_{t}\right)=1-$ $\exp \left(-\theta_{t} \exp \left(-\lambda \bar{x}_{t}\right)\right)$, and the expectation of the maximum value of the housing services, conditional on this value exceeding the threshold $\bar{x}_{t}$, is $E\left[x_{(1) t} \mid x_{(1) t} \geq \bar{x}_{t}\right]=\bar{x}_{t}+\frac{\int_{\bar{x}_{t}}^{\infty} \pi\left(x, \theta_{t}\right) d x}{\pi\left(\bar{x}_{t}, \theta_{t}\right)}=$ $\bar{x}_{t}+\frac{\varphi\left(\theta_{t}\left(1-F\left(\bar{x}_{t}\right)\right)\right.}{\lambda \pi\left(\bar{x}_{t}, \theta_{t}\right)}$.

Proof. First, consider the probability of distributing the house in period $t$. If $N$ buyers showed up, the probability that the house is distributed is the probability that the maximum value of $x$ exceeds the threshold value $\bar{x}_{t}$. Then the overall probability that the house is distributed is

$$
\begin{gathered}
P(\text { House distributed in } t)=E_{N} P\left(x_{(1) t} \geq \bar{x}_{t}, N\right)=E_{N}\left(1-F\left(\bar{x}_{t}\right)^{N}\right)= \\
=\sum_{n=0}^{\infty} e^{-\theta_{t}} \frac{\theta_{t}^{n}}{n !}\left(1-F\left(\bar{x}_{t}\right)^{n}\right)=1-e^{-\theta_{t}} e^{\theta F\left(\bar{x}_{t}\right)}=\left(1-e^{-\theta_{t}\left(1-F\left(\bar{x}_{t}\right)\right)}\right)=\pi\left(\bar{x}_{t}, \theta_{t}\right)
\end{gathered}
$$

Second, the expected maximal value of the housing services $x$, conditional on exceeding the distributional threshold $\bar{x}_{t}$ is

$$
E\left[x_{(1)} \mid x_{(1)} \geq \bar{x}\right]=\frac{E_{N} \int_{\bar{x}}^{\infty} x d F(x)^{N}}{E_{N}\left(1-F(\bar{x})^{N}\right)}
$$

where $F(x)^{N}$ is a cdf of the maximum of the draws of housing services $x$.

Denote $A(N)=\int_{\bar{x}}^{\infty} x d F(x)^{N}$, then

$$
\begin{array}{r}
A(N)=\int_{\bar{x}}^{\infty} x d F(x)^{N}=\int_{\bar{x}}^{\infty} x N F(x)^{N-1} d F(x)= \\
=-\int_{\bar{x}}^{\infty} x N F(x)^{N-1} d(1-F(x))=-N\left[\int_{\bar{x}}^{\infty} x F(x)^{N-1} d(1-F(x))\right]= \\
=-N\left[\left.x F(x)^{N-1}(1-F(x))\right|_{\bar{x}} ^{\infty}-\int_{\bar{x}}^{\infty}(1-F(x)) d\left(x F(x)^{N-1}\right)\right]= \\
=-N\left[-\bar{x} F(\bar{x})^{N-1}(1-F(\bar{x}))-\int_{\bar{x}}^{\infty}(1-F(x))\left[F(x)^{N-1} d x+(N-1) F(x)^{N-2} x d F(x)\right]=\right. \\
=N \bar{x} F(\bar{x})^{N-1}(1-F(\bar{x}))+N \int_{\bar{x}}^{\infty}(1-F(x)) F(x)^{N-1} d x+N \int_{\bar{x}}^{\infty}(1-F(x)) x d F(x)^{N-1}
\end{array}
$$

where the last term $N \int_{\bar{x}}^{\infty}(1-F(x)) x d F(x)^{N-1}$ can be further rewritten as

$$
\begin{array}{r}
N \int_{\bar{x}}^{\infty}(1-F(x)) x d F(x)^{N-1}=N \int_{\bar{x}}^{\infty} x d F(x)^{N-1}-N \int_{\bar{x}}^{\infty} F(x) x d F(x)^{N-1}= \\
=N A(N-1)-N(N-1) \int_{\bar{x}}^{\infty} x F(x) F(x)^{N-2} d F(x)= \\
=N A(N-1)-(N-1) \int_{\bar{x}}^{\infty} x N F(x)^{N-1} d F(x)=N A(N-1)-(N-1) \int_{\bar{x}}^{\infty} x d F(x)^{N}= \\
=N A(N-1)-(N-1) A(N)
\end{array}
$$


Hence, in equation (76)

$$
A(N)=N \bar{x} F(\bar{x})^{N-1}(1-F(\bar{x}))+N \int_{\bar{x}}^{\infty}(1-F(x)) F(x)^{N-1} d x+N A(N-1)-(N-1) A(N)(78)
$$

After cancelling $A(N)$ from both sides we arrive at

$$
\begin{gathered}
N(A(N)-A(N-1))=N \bar{x} F(\bar{x})^{N-1}(1-F(\bar{x}))+N \int_{\bar{x}}^{\infty}(1-F(x)) F(x)^{N-1} d x \\
A(N)-A(N-1)=\bar{x} F(\bar{x})^{N-1}(1-F(\bar{x}))+\int_{\bar{x}}^{\infty}(1-F(x)) F(x)^{N-1} d x \\
A(N)-A(0)=\sum_{n=1}^{N}(A(n)-A(n-1))=\sum_{n=1}^{N} \bar{x} F(\bar{x})^{n-1}(1-F(\bar{x}))+\sum_{n=1}^{N} \int_{\bar{x}}^{\infty}(1-F(x)) F(x)^{n-1} d x(81)
\end{gathered}
$$

where $A(0)=0$,

$$
\begin{gathered}
\sum_{n=1}^{N} F(\bar{x})^{n-1}=\frac{1-F(\bar{x})^{N}}{1-F(\bar{x})} \\
A(N)=\bar{x} \frac{1-F(\bar{x})^{N}}{1-F(\bar{x})}(1-F(\bar{x}))+\int_{\bar{x}}^{\infty}(1-F(x)) \frac{1-F(\bar{x})^{N}}{1-F(\bar{x})} d x \\
A(N)=\bar{x}\left(1-F(\bar{x})^{N}\right)+\int_{\bar{x}}^{\infty}\left(1-F(\bar{x})^{N}\right) d x \\
E_{N} A(N)=\bar{x} E_{N}\left(1-F(\bar{x})^{N}\right)+\int_{\bar{x}}^{\infty} E_{N}\left(1-F(\bar{x})^{N}\right) d x \\
E_{N} A(N)=\bar{x} \pi\left(\bar{x}, \theta_{t}\right)+\int_{\bar{x}}^{\infty} \pi\left(x, \theta_{t}\right) d x
\end{gathered}
$$

Hence,

$$
E\left[x_{(1)} \mid x_{(1)} \geq \bar{x}\right]=\bar{x}+\frac{\int_{\bar{x}}^{\infty} \pi(x, \theta) d x}{\pi(\bar{x}, \theta)}
$$

where

$$
\begin{aligned}
\int_{\bar{x}}^{\infty} \pi(x, \theta) d x & =\int_{\bar{x}}^{\infty}\left(1-e^{-\theta(1-F(x))}\right) d x=-\frac{1}{\lambda} \int_{\bar{x}}^{\infty} \frac{\left(1-e^{-\theta(1-F(x))}\right)}{\theta(1-F(x))} d \theta(1-F(x))= \\
= & -\frac{1}{\lambda} \int_{\theta(1-F(\bar{x}))}^{0} \frac{1-e^{-t}}{t} d t=\frac{1}{\lambda} \int_{0}^{\theta(1-F(\bar{x}))} \frac{1-e^{-t}}{t} d t=\frac{1}{\lambda} \varphi(\theta(1-F(\bar{x})))
\end{aligned}
$$

and

$$
E\left[x_{(1)} \mid x_{(1)} \geq \bar{x}\right]=\bar{x}+\frac{\varphi(\theta(1-F(\bar{x})))}{\lambda \pi(\bar{x}, \theta)}
$$




\section{A.2.1 The system describing the solution of the social planner problem}

The recursive representation of the social planner problem with the value function $\Omega_{t}\left(B_{t}, S_{t}, z_{t}\right)$ is

$$
\begin{aligned}
\Omega_{t}\left(B_{t}, S_{t}\right) & =\max _{\bar{x}_{t}, H_{t}, B_{t}^{a}, S_{t}^{a}}\left[\frac{\beta}{1-\beta} S_{t}^{a}\left[\bar{x}_{t} \pi_{t}\left(\bar{x}_{t}, \theta_{t}\right)+\frac{\varphi_{t}\left(\theta_{t}\left(1-F\left(\bar{x}_{t}\right)\right)\right)}{\lambda}\right]-w B_{t}-c^{b} B_{t}^{a}-c^{s} S_{t}^{a}-T C\left(H_{t}(9 \oplus)\right.\right. \\
& \left.+\beta \Omega_{t+1}\left(B_{t+1}, S_{t+1}\right)+\mu_{t}^{B}\left(B_{t}-B_{t}^{a}\right)+\mu_{t}^{S}\left(S_{t}-S_{t}^{a}\right)\right] \\
B_{t+1} & =B_{t}+d-\pi\left(\bar{x}_{t}, \theta_{t}\right) S_{t}^{a} \\
S_{t+1} & =S_{t}+h_{t}-\pi\left(\bar{x}_{t}, \theta_{t}\right) S_{t}^{a}
\end{aligned}
$$

where $\mu_{t}^{B}, \mu_{t}^{S}$ are the Lagrangian multipliers for constraints $S_{t}^{a} \leq S_{t}$ and $B_{t}^{a} \leq B_{t}$.

The first-order conditions with respect to $\bar{x}, H_{t}, B_{t}^{a}, S_{t}^{a}$, correspondingly, are

$$
\begin{aligned}
\bar{x}_{t} & =(1-\beta)\left(\frac{\partial \Omega_{t+1}}{\partial B_{t+1}}+\frac{\partial \Omega_{t+1}}{\partial S_{t+1}}\right) \text { or } S_{t}^{a}=0 \\
M C\left(H_{t}\right) & =\beta \frac{\partial \Omega_{t+1}}{\partial S_{t+1}} \\
\mu_{t}^{B} & =\max \left\{\frac{\beta}{1-\beta} \frac{1}{\lambda} \frac{\pi\left(\bar{x}_{t}, \theta_{t}\right)}{\theta_{t}}-c^{b}, 0\right\} \\
\mu_{t}^{S} & =\max \left\{\frac{\beta}{1-\beta} \frac{1}{\lambda}\left(\varphi\left(\theta_{t}\left(1-F\left(\bar{x}_{t}\right)\right)\right)-\pi\left(\bar{x}_{t}, \theta_{t}\right)\right)-c^{s}, 0\right\}
\end{aligned}
$$

and the envelope conditions are

$$
\begin{aligned}
& \frac{\partial \Omega_{t}}{\partial B_{t}}=-w+\beta \frac{\partial \Omega_{t+1}}{\partial B_{t+1}}+\mu_{t}^{B} \\
& \frac{\partial \Omega_{t}}{\partial S_{t}}=\beta \frac{\partial \Omega_{t+1}}{\partial S_{t+1}}+\mu_{t}^{S}
\end{aligned}
$$

\section{A.2.2 The comparison of the equilibrium allocations in the auction model and the constrained Pareto optimal allocation in the steady state}

To compare the main variables in the auction equilibrium allocation and the constrained Pareto efficient allocation, consider the following lemma, that compares the product $z=\theta(1-F(\bar{x})=$ $\theta e^{-\lambda \bar{x}}$, the "share of eligible active buyers", buyers with values above the threshold value $\bar{x}$.

Lemma 4. In the auction model $z$ is lower than in the social optimum.

Proof. Denote $z^{A}, z^{0}$ the equilibrium value in the auction model and the socially efficient value. In the auction

$$
\varphi\left(z^{A}\right)=\frac{\lambda(1-\beta)\left(c_{s}+(1-\beta) V^{S}\right)}{\beta}=\frac{\lambda(1-\beta)}{\beta}\left((1-\beta) V^{S}+c_{s}\right)
$$

where in the auction $V^{S}=\frac{M C(d)}{\beta}$. 
Table 4: The steady-state equilibrium allocation in the auction and the social planner allocation.

\begin{tabular}{|c|c|c|c|}
\hline & Auction & Th & Social planner \\
\hline Construction $H$ & $\bar{H} H=d$ & $=$ & $\bar{H} H=d$ \\
\hline Seller v.f. $V^{S}$ & $V^{S}=\frac{\psi d+c^{h}}{\beta}$ & & - \\
\hline Product $z=\theta e^{-\lambda \bar{x}}$ & $\varphi(z)=\frac{\lambda(1-\beta)\left(c_{s}+(1-\beta) V^{S}\right)}{\beta}$ & $\leq$ & $\varphi(z)-\pi(z)=\lambda\left(\frac{1-\beta}{\beta}\right)^{2}\left(M C(d)+\frac{\beta}{1-\beta} c^{s}\right)$ \\
\hline Prob of sale $\pi$ & $1-\exp (-z)$ & $\leq$ & $1-\exp (-z)$ \\
\hline Prices $p$ & $V^{S}+\frac{\varphi(z)}{\lambda(1-\beta) \pi(z)}$ & & - \\
\hline Threshold $\bar{x}$ & $\bar{x}=\frac{1}{\lambda}+\frac{\beta \pi}{\lambda(1-\beta) z e^{\lambda \bar{x}}}+\frac{(1-\beta)}{\beta} M C(d)-c_{b}-w$ & $\geq$ & $\bar{x}=\frac{\beta}{1-\beta} \frac{\pi}{\lambda \theta}+\frac{1-\beta}{\beta} M C(d)-c^{b}-w$ \\
\hline Tightness $\theta$ & $z e^{\lambda \bar{x}}$ & $\lessgtr$ & $z e^{\lambda \bar{x}}$ \\
\hline Buyer v.f. $V^{B}$ & $\frac{1}{1-\beta}\left(\frac{\beta \pi}{\lambda(1-\beta) \theta}-c_{b}-w\right)$ & & - \\
\hline$\#$ sellers $S$ & $d / \pi$ & $>$ & $d / \pi$ \\
\hline \# buyers $B$ & $S \theta$ & $\lessgtr$ & $S \theta$ \\
\hline
\end{tabular}

Notes: "v.f." stands for "value function", \# stands for "number of". The value functions of buyer, seller and prices are not defined in the social planner problem. The column 'Th' in the middle compare the values in the models for any parameter values. The last column compares the social planner allocation with the equilibrium allocation in the auctions. The sign $\lessgtr$ means that the comparison depends on the parameter values and can go in either direction.

$$
\begin{array}{r}
\varphi\left(z^{A}\right)=\frac{\lambda(1-\beta)}{\beta}\left((1-\beta) \frac{M C(d)}{\beta}+c_{s}\right)=\lambda\left(\frac{(1-\beta)}{\beta}\right)^{2} M C(d)+\lambda \frac{(1-\beta)}{\beta} c^{s}= \\
=\varphi\left(z^{0}\right)-\pi\left(z^{0}\right) \leq \varphi\left(z^{0}\right)
\end{array}
$$

where the last inequality holds, because the probability is non-negative. Since $\varphi($.$) is an increasing$ function, hence $z^{A} \leq z^{0}$.

Using lemma 4 we can now show that the probability of distributing the house in the social optimum is higher as compared with the probability of sale in the auction model, and that the threshold value picked by the social planner is lower than the correponding value in the auction.

Lemma 5. The probability of distributing the house $\pi$ in the constrained Pareto efficient allocation is higher than the probability of sale in the auction model. The threshold value for transaction, $\bar{x}$, in the social planner is lower than the value picked by the seller in the auction model. The number of sellers is greater in the auction model as compared to what is socially efficient.

Proof. The comparison of probabilities follows immediately from lemma 2 , because $z^{0} \geq z^{A}$ and $\pi=1-\exp (-z)$ is an increasing function, $\pi\left(z^{0}\right) \geq \pi\left(z^{A}\right)$. The comparison of the number of sellers in the two setups directly follows from the comparison of these probabilities.

To prove the relationship between the threshold values, consider the relationship between the threshold values $\bar{x}$ in the auction and social optimum, which is

$$
\bar{x}^{A}-\frac{\beta}{\lambda(1-\beta)} \frac{\pi\left(z^{A}\right)}{z^{A}} \exp \left(-\lambda \bar{x}^{A}\right)-\frac{1}{\lambda}=\bar{x}^{0}-\frac{\beta}{\lambda(1-\beta)} \frac{\pi\left(z^{0}\right)}{z^{0}} \exp \left(-\lambda \bar{x}^{0}\right)
$$


or

$$
\bar{x}^{A}-\bar{x}^{0}=\frac{\beta}{\lambda(1-\beta)} \frac{\pi\left(z^{A}\right)}{z^{A}} \exp \left(-\lambda \bar{x}^{A}\right)-\frac{\beta}{\lambda(1-\beta)} \frac{\pi\left(z^{0}\right)}{z^{0}} \exp \left(-\lambda \bar{x}^{0}\right)+\frac{1}{\lambda}
$$

where the function $\pi(z) / z$ is decreasing, because the function $\varphi(z)$ is concave

$$
\begin{array}{r}
\varphi^{\prime}(z)=\pi(z) / z=(1-\exp (-z)) / z \\
\varphi^{\prime \prime}(z)=\frac{\exp (-z) z-(1-\exp (-z))}{z^{2}}=\frac{\exp (-z)(z+1)-z}{z^{2}}<0
\end{array}
$$

where $\exp (-z)(z+1)<1$, since $\exp (z)>z+1$.

Now we can use the proof by contradiction. Let assume $x^{0}>x^{A}$, then $\exp \left(\lambda x^{0}\right)>\exp \left(\lambda x^{A}\right)$ and

$$
\exp \left(-\lambda x^{0}\right)<\exp \left(-\lambda x^{A}\right)
$$

From (102), we also have

$$
\frac{\beta}{\lambda(1-\beta)} \frac{\pi\left(z^{A}\right)}{z^{A}} \exp \left(-\lambda \bar{x}^{A}\right)-\frac{\beta}{\lambda(1-\beta)} \frac{\pi\left(z^{0}\right)}{z^{0}} \exp \left(-\lambda \bar{x}^{0}\right)+\frac{1}{\lambda}<0
$$

Hence,

$$
\begin{array}{r}
\frac{\beta}{\lambda(1-\beta)} \frac{\pi\left(z^{A}\right)}{z^{A}} \exp \left(-\lambda \bar{x}^{0}\right)-\frac{\beta}{\lambda(1-\beta)} \frac{\pi\left(z^{0}\right)}{z^{0}} \exp \left(-\lambda \bar{x}^{0}\right)+\frac{1}{\lambda} \\
<\frac{\beta}{\lambda(1-\beta)} \frac{\pi\left(z^{A}\right)}{z^{A}} \exp \left(-\lambda \bar{x}^{A}\right)-\frac{\beta}{\lambda(1-\beta)} \frac{\pi\left(z^{0}\right)}{z^{0}} \exp \left(-\lambda \bar{x}^{0}\right)+\frac{1}{\lambda}<0
\end{array}
$$

Then

$$
\frac{\beta}{\lambda(1-\beta)} \frac{\pi\left(z^{A}\right)}{z^{A}} \exp \left(-\lambda \bar{x}^{0}\right)-\frac{\beta}{\lambda(1-\beta)} \frac{\pi\left(z^{0}\right)}{z^{0}} \exp \left(-\lambda \bar{x}^{0}\right)+\frac{1}{\lambda}<0
$$

or

$$
\frac{\pi\left(z^{A}\right)}{z^{A}}-\frac{\pi\left(z^{0}\right)}{z^{0}}<-\frac{1}{\lambda} \exp \left(\lambda \bar{x}^{0}\right) \frac{\lambda(1-\beta)}{\beta}<0
$$

Implying that $z^{A}>z^{0}$ which contradicts previously proved $z^{A} \leq z^{0}$. Hence $x^{A} \geq x^{0}$ 